\title{
On the use of ELF/VLF emissions triggered by HAARP to simulate PLHR and to study associated MLR events
}

\author{
Michel Parrot ${ }^{1,2^{*}}$ (D, Frantisěk Němec ${ }^{3^{*}}$, Morris B. Cohen ${ }^{4^{*}}$ and Mark Gołkowski $5^{5^{*}}$
}

\begin{abstract}
A spectrogram of Power Line Harmonic Radiation (PLHR) consists of a set of lines with frequency spacing corresponding exactly to 50 or $60 \mathrm{~Hz}$. It is distinct from a spectrogram of Magnetospheric Line Radiation (MLR) where the lines are not equidistant and drift in frequency. PLHR and MLR propagate in the ionosphere and the magnetosphere and are recorded by ground experiments and satellites. If the source of PLHR is evident, the origin of the MLR is still under debate and the purpose of this paper is to understand how MLR lines are formed. The ELF waves triggered by Highfrequency Active Auroral Research Program (HAARP) in the ionosphere are used to simulate lines (pulses of different lengths and different frequencies). Several receivers are utilized to survey the propagation of these pulses. The resulting waves are simultaneously recorded by ground-based experiments close to HAARP in Alaska, and by the low-altitude satellite DEMETER either above HAARP or its magnetically conjugate point. Six cases are presented which show that 2-hop echoes (pulses going back and forth in the magnetosphere) are very often observed. The pulses emitted by HAARP return in the Northern hemisphere with a time delay. A detailed spectral analysis shows that sidebands can be triggered and create elements with superposed frequency lines which drift in frequency during the propagation. These elements acting like quasi-periodic emissions are subjected to equatorial amplification and can trigger hooks and falling tones. At the end all these known physical processes lead to the formation of the observed MLR by HAARP pulses. It is shown that there is a tendency for the MLR frequencies of occurrence to be around $2 \mathrm{kHz}$ although the exciting waves have been emitted at lower and higher frequencies.
\end{abstract}

Keywords: Ionospheric heating, Power Line Harmonic Radiation, Magnetospheric Line Radiation, HAARP, DEMETER

\footnotetext{
*Correspondence: mparrot@cnrs-orleans.fr; frantisek.nemec@gmail.com;

mcohen@gatech.edu; mark.golkowski@ucdenver.edu

${ }^{1}$ LPC2E/CNRS, Orléans, France

${ }^{3}$ Faculty of Mathematics and Physics, Charles University, Prague, Czech

Republic

${ }^{4}$ School of Electrical and Computer Engineering, Georgia Institute

of Technology, Atlanta, GA, USA

${ }^{5}$ Department of Electrical Engineering, University of Colorado Denver,

Denver, CO, USA

Full list of author information is available at the end of the article
} 


\section{Graphical Abstract}

The HF carrier frequency emitted by HAARP is modulated to trigger in the bottom of the ionosphere ( $\sim 80 \mathrm{~km})$ pulses at ELF/VLF frequencies which are simultaneously recorded by the low altitude satellite DEMETER $(660 \mathrm{~km})$ and the ground station Chistochina.
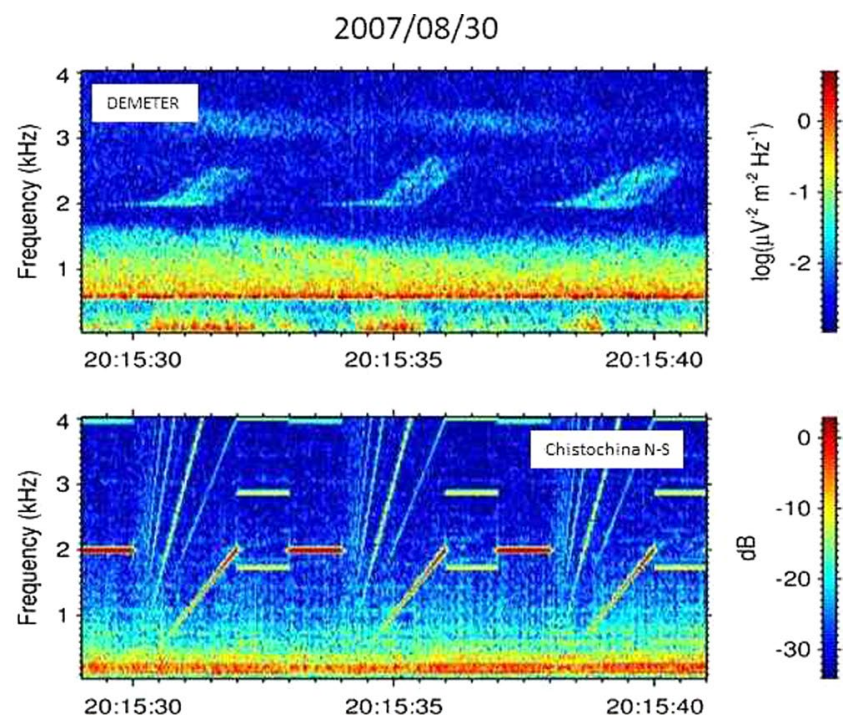

\section{Introduction}

Power Line Harmonic Radiation (PLHR) are electromagnetic man-made waves at harmonic frequencies of 50 or $60 \mathrm{~Hz}$. They have been observed on ground over many decades (Helliwell et al. 1975; Park and Helliwell 1978, 1981, 1983; Matthews and Yearby 1978; Yearby et al. 1983; Manninen 2005). Observations by satellite have been also done on a case basis (Bell et al. 1982; Koons et al. 1978; Tomizawa and Yoshino 1985; Rodger et al. 1995). In frequency-time spectrograms they look like a set of parallel lines with distances of 50/100 or 60/120 Hz. Using DEMETER data, Němec et al. (2006) have developed a procedure for an automatic detection of PLHR events between $500 \mathrm{~Hz}$ and $4 \mathrm{kHz}$. They have detected events with frequency spacing of spectral lines of $50 / 100 \mathrm{~Hz}$ and with frequency spacing of $60 / 120 \mathrm{~Hz}$ which very well correspond to the frequencies of electric power systems in the possible regions of generation below or in their magnetically conjugate areas. Other properties of PLHR occurrence observed by DEMETER can be found in Němec et al. (2008). Němec et al. (2010) did not find that the intensity of the natural electromagnetic waves measured over industrialized areas and magnetically conjugate regions is larger than elsewhere. PLHR observed at $50 / 60 \mathrm{~Hz}$ and low harmonics have been studied by Dudkin et al. (2015) and Němec et al. (2015), who were looking also for a weekend effect (Park and Miller 1979). Such an effect is possibly present above the European region, but it is very weak. They have further shown that the PLHR effects are less often detected in the summer, because on one hand the ionospheric absorption increases, and on the other hand the PLHR are masked by lightning generated emissions. However, on a case basis Parrot et al. (2014) have related triggered emissions due to PLHR propagating in the magnetosphere and suffering wave-particle interactions in the equatorial region. There are rising tones or hooks with a starting frequency associated to a parent line at a frequency multiple of 50 or $60 \mathrm{~Hz}$. These triggered emissions occurred more frequently at high latitudes $(3<L<6)$.

However, different sets of lines not separated by $50 / 100$ or by $60 / 120 \mathrm{~Hz}$ have been observed either with satellites (Rodger et al. 1995) or with ground-based experiments (Rodger et al. 1999, 2000a, b; Yearby 1982). These lines usually drift in frequency and they are called Magnetospheric Line Radiation (MLR). Their origin is not completely known and in particular their possible relation with PLHR has been extensively discussed for a long time. For example, Kostrov et al. (2017) claimed that the nature of the generation of MLR and PLHR is the same. They said that the only difference is that MLR passed through unstable plasma, while PLHR propagated in calm conditions.

Onboard DEMETER, MLR have been observed by Němec et al. (2007) who have compared their relative occurrence with PLHR. For example, PLHR events are more intense during the night than during the day, whereas no dependence of MLR peak intensities on magnetic local time was found. Other properties of MLR events seen by DEMETER are reported by Němec et al. (2009a). In particular, they have shown a remarkable daytime event where PLHR are observed in 
the North hemisphere and MLR in the same frequency range are observed in the conjugate region in the South hemisphere half an hour later. Different features of MLR have been studied by Němec et al. (2012a, b). It includes a MLR event observed simultaneously on board DEMETER and CLUSTER 1 and 2 satellites during a perigee passage at a radial distance of about $4 R_{\mathrm{E}}$. Although the two CLUSTER satellites are separated by $\sim 0.7 \mathrm{~L}$-shells, the wave pattern is identical on both. They have shown that the waves cross the geomagnetic equator over a significant range of L-shells (3.9-4.6). Considering that the DEMETER satellite was separated by about $1.8 \mathrm{~h}$ in MLT from the Cluster spacecraft this indicates a significant azimuthal extent of the source.

Comparisons between ground-based and DEMETER observations have been done. Large-scale MLR have been observed simultaneously on ground at Kannuslehto $\left(67.74^{\circ} \mathrm{N}, 26.27^{\circ} \mathrm{E}, L=5.41\right)$ in Finland and on board DEMETER which was flying just above (Parrot et al. 2007). This 2-h-long event was recorded over a large area in the Northern hemisphere and in the conjugate region. They claimed that these MLR could be due to PLHR propagating in the ionosphere and the magnetosphere, and undergoing a nonlinear interaction with particles when they cross the equator. A similar MLR event simultaneously observed on ground in the Northern hemisphere and in the conjugate region by DEMETER has been reported by Nermec et al. (2009b). They have shown that the individual lines of the event are formed (at least for this particular case) by elements going back and forth between the Northern and Southern hemispheres.

MLR events and associated triggered emissions observed by DEMETER have been reported by Parrot and Nermec (2009). They said that, on one hand some MLR events are due to PLHR which may suffer a nonlinear gyro-resonant interaction at the magnetic equator, but on the other hand quasi-periodic (QP) emissions are very often associated with the MLR, and then the origin of these waves is natural. In that case, the appearance of lines in the spectrograms is caused by the periodicity and the frequency band limits of the QP individual elements.

Using the whole DEMETER data set, Bezděková et al. (2015) have studied the occurrence of MLR events with solar wind parameters and geomagnetic indices. They have found that MLR events occur more often after periods of enhanced geomagnetic activity, and more often during the northern winter and spring than during the northern summer. Later on, Bezděková et al. (2019) searched for a possible relation between these electromagnetic waves having either a frequency modulation (MLR) or a time modulation (QP emissions). All in all, 1152 MLR events and 2172 QP emissions have been analyzed, but they have not found a relation between the properties of QP and MLR events observed at the same times.

The purpose of this work is to use the waves triggered by High-frequency Active Auroral Research Program (HAARP) as a simulation of PLHR emissions with the aim to see their possible effects, to understand how MLR are formed, and to check the role of the QP emissions. In this paper, we first briefly present the experiments (HAARP and DEMETER) together with previous results from HAARP. Next, we describe five cases simultaneously recorded by ground-based receivers in Alaska and by the satellite DEMETER. Then, a wave propagation analysis of the triggered signals is done for a sixth case. Finally, discussions are displayed and conclusions are given.

\section{The experiments HAARP}

HAARP uses powerful radio waves at $\mathrm{HF}(3-30 \mathrm{MHz})$ to heat the ionospheric plasma. It is located near Gakona in Alaska. Its geographic coordinates are $62.4^{\circ} \mathrm{N}$ in latitude and $145.2^{\circ} \mathrm{W}$ in longitude, its magnetic conjugate point is located at $56.67^{\circ} \mathrm{S}, 174.48^{\circ} \mathrm{E}$ (Gołkowski 2009), and its McIlwain parameter $L$ is equal to 4.9. The ONOFF modulation of the HF wave at ELF/VLF rates, allows HF energy to be converted into ELF/VLF radiation (see Sheerin and Cohen 2015 and references therein). Various configurations of the HF heating have been experimented to determine the best wave generation (Cohen 2009, Cohen et al. 2011, 2012). To study the induced ionospheric effects many ground-based experiments are associated to HAARP, and in particular, ELF/VLF data are registered with broadband high-sensitivity receivers which consist of two orthogonal air-core loop antennae, measuring the two horizontal components of the magnetic field between $300 \mathrm{~Hz}$ and $40 \mathrm{kHz}$. The N-S antenna is sensitive to TEM mode waves arriving from the north or the south, whereas E-W is for the east or west direction. Details of this experiment can be found in Cohen et al. (2010a). In our paper data from two receivers located at Chistochina $\left(62.61^{\circ} \mathrm{N}, 144.62^{\circ} \mathrm{W}, 37 \mathrm{~km}\right.$ from HAARP), and Juneau $\left(58.59^{\circ} \mathrm{N}, 134.90^{\circ} \mathrm{W}, 704 \mathrm{~km}\right.$ SE of HAARP) are used. Their data are available from a web server named WALDO which is presented in Cohen (2020).

\section{Previous results from HAARP heating}

In this section, previous results in relation with our study are briefly presented. Inan et al. (2004) have observed at Chistochina up to 10-hop multiple reflected ELF/ VLF signals going back and forth between the Northern hemisphere and the Southern hemisphere. They noticed amplification and triggering of emissions at each 
crossing of the equatorial interaction region. Cohen et al. (2008) have found that the orientation of the effective HAARP electric dipole is generally oriented in the magnetic east-west direction. They used data from two ELF/ VLF receivers located at $700 \mathrm{~km}$ from HAARP (including Chistochina). To detect 1-hop signal, very important experiments have been implemented on the open sea at the conjugate point of HAARP (a ship-borne receiver and two autonomous buoy platforms) and results have been presented by Gołkowski et al. (2008). The observed signals are accompanied by triggered emissions and exhibit temporal amplification of $15-25 \mathrm{~dB} / \mathrm{s}$ and spectral broadening to $50 \mathrm{~Hz}$. The 1-hop propagation time was $4.2 \mathrm{~s}$, very similar to the $4 \mathrm{~s}$ propagation time from previous observations of HAARP echoes made by Inan et al. (2004). They also noticed that only certain components of the frequency-time formats transmitted are amplified. Another work reported by Golkowski et al. (2010) shows that echoes were produced only for frequencies between 2.0 and $2.8 \mathrm{kHz}$ although single-frequency signals between 1 and $3 \mathrm{kHz}$ and frequency sweeps from 0.5 to $3.5 \mathrm{kHz}$ were injected. They claimed that it is due to resonance with anisotropic electrons with energy of 5 to $10 \mathrm{keV}$. A comparison by Hosseini et al. (2017) indicates that there is a similar evolution between chorus risers and 2-hop echoes of a single-frequency signal which presents triggered emissions. The occurrence of sidebands around the carrier frequency of pulses is discussed in a review by Gołkowski et al. (2019) who additionally examine the frequencies of the observed echoes which are missing (see also "Discussions" later on). One can see additional results in review papers by Cohen and Gołkowski (2013), and recently by Guo et al. (2021). Overall, ELF/VLF magnetospheric wave injection experiments with HAARP show that the facility injects ELF/VLF waves into the magnetosphere primarily from directly above the heated portion of the ionosphere (Golkowski et al. 2011).

\section{DEMETER}

DEMETER was a low-altitude satellite $(660 \mathrm{~km})$ in operation between 2004 and 2010 onto a polar and circular orbit. It measured electromagnetic waves and plasma parameters all around the Earth (Parrot 2006). The orbit of DEMETER was nearly sun-synchronous. The upgoing half-orbits correspond to nighttime (2230 LT) and the downgoing half-orbits correspond to daytime (1030 LT). The instruments are operated in two scientific modes (i) a survey mode where spectra of one electric and one magnetic component are computed onboard up to $20 \mathrm{kHz}$ with a frequency resolution of $19.5 \mathrm{~Hz}$ and a time resolution of $2 \mathrm{~s}$; (ii) a burst mode where waveforms of one electric field component and one magnetic component are recorded up to $20 \mathrm{kHz}$. In this burst mode the waveforms of the six components of the electromagnetic field up to $1.25 \mathrm{kHz}$ are also recorded to allow a wave propagation analysis.

Due to technical reasons, data were only recorded at invariant latitudes less than $65^{\circ}$ except for special campaigns over HAARP or its magnetically conjugate region. Several studies have been already done during these special campaigns for ELF/VLF generation experiments conducted by the HF heating facilities at HAARP (see, e.g., Platino et al. 2006; Piddyachiy et al. 2008; Piddyachiy 2012).

\section{The cases}

The cases are defined by the DEMETER half-orbit number and the date. For each case, we have several sets of data: (i) the parent emissions (pulses, ramps) which are scheduled, and then, which must be triggered by HAARP; (ii) the emissions really recorded by ground-based receivers close to HAARP (Chistochina and Juneau), and (iii) the emissions registered onboard DEMETER in the ionosphere close to HAARP or its magnetically conjugate point. One must say that the pulses of different lengths are emitted by HAARP in a frequency band where PLHR have been observed, but harmonics are sometimes also generated (see for example Gołkowski 2009).

For the ground station spectrograms, we used an FFT length of 16,384 points (the sampling frequency is $100 \mathrm{kHz}$ ) and an FFT length of $16,384 / 2.5$ points for the DEMETER spectrograms (to achieve the same frequency resolution with the sampling frequency of only $40 \mathrm{kHz}$ ). We always used $50 \%$ overlapping and averaged over two subsequent spectra. To have spectrograms with a better time resolution, we use an FFT length of 3250 for ground stations and of $3250 / 2.5=1300$ for DEMETER. By that we achieve the same frequency and time resolution $(\sim 31 \mathrm{~Hz}$ and $0.0325 \mathrm{~s})$ for both the ground and satellite observations.

When it was necessary the Chistochina and Juneau data have been processed through a filter that removes the power line harmonic noise from the local power lines using a method described in Cohen et al. (2010b).

\section{Case 1: $16781 \_0: 2007 / 08 / 23$ daytime}

This case 1 concerns data recorded when DEMETER is in the Southern hemisphere close to the HAARP conjugate point during day time. The corresponding halforbit is shown in Fig. 1 and the recorded spectrogram by DEMETER between 0 and $4 \mathrm{kHz}$ is shown in Fig. 2 (see also Fig. 2.8 of Gołkowski 2009, and Fig. 7.1 and 7.2 of Piddyachiy 2012). In this case, two 1-s pulses are simultaneously emitted at $2011 \mathrm{~Hz}$ and $1973 \mathrm{~Hz}$ followed by a 2 -s ramp between 0 and $2 \mathrm{kHz}$ and one 1 -s pulse at $571 \mathrm{~Hz}$ (see Fig. 3). One can see pulses at the 


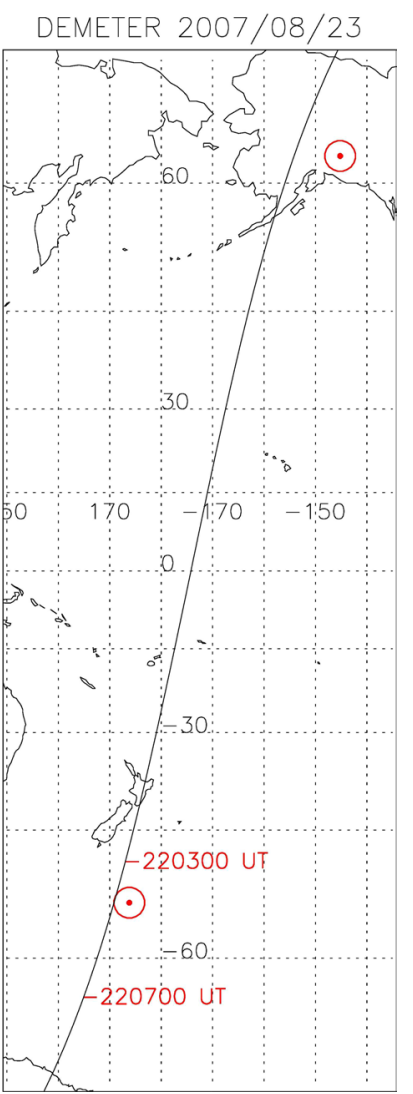

Fig. 1 Trace of the DEMETER half-orbit recorded on August 23, 2007 with times. The positions of HAARP and its conjugate point are indicated by red dots and circles. The advantage of a day time half-orbit is that if the track is close to HAARP in the Northern hemisphere, it is also close to the HAARP conjugate point a few tens of minutes after in the Southern hemisphere

specific frequency $1973 \mathrm{~Hz}$ with triggered emissions. As DEMETER is in the Southern hemisphere, they are 1-hop pulses. The complete time interval of pulse observation by DEMETER is between 22:03:00 and 22:07:00 UT (see Fig. 1). It is well around the HAARP conjugate point and this gives an evaluation of the zone illuminated by HAARP in the Southern hemisphere, i.e., between $-50.01^{\circ} \mathrm{S}$ and $-64.15^{\circ} \mathrm{S}$ in geographic latitude. One can see that the set of pulses at $1713 \mathrm{~Hz}$ (the third harmonic of $571 \mathrm{~Hz}$ ) does not trigger emissions. Figure 4 displays more detailed spectrograms of data simultaneously recorded by DEMETER (top panel) and at Juneau (bottom panel). Juneau does not see the original pulses because they are perhaps too weak, but after an amplification at the equator Juneau sees 2-hop triggered emissions. It is possible to identify the same triggered elements on DEMETER and at Juneau and then to calculate the time for travel between hemispheres. There are $4.0 \mathrm{~s}$ between
DEMETER and Juneau for the 3 triggered emissions indicated in Fig. 4. This is the expected time for a 1-hop travel (Gołkowski et al. 2008). No data were recorded at Chistochina.

This is a nice example with triggered emissions from pulses and also it is noticed that the pulses can trigger emissions only at a specific frequency (around $2 \mathrm{kHz}$ ). It is also interesting to note that the triggered elements seen by Juneau in the Northern hemisphere are very similar to the triggered elements observed by DEMETER in the Southern hemisphere. As the triggered elements seen by Juneau cross two times the equatorial interaction region, it means that the nonlinear triggering mechanism is less effective for emissions which are less coherent than the original pulses.

\section{Case 2: 16883_0: 2007/08/30 daytime}

The frequency pattern is similar to the previous one in case 1 (see Fig. 3).The spectrogram in Fig. 5 shows that pulses and triggered emissions are observed by DEMETER in the Northern hemisphere (see also Fig. 7.9 and 7.10 of Piddyachiy 2012). In fact the pulses with triggered emissions are observed since 20:12:20 UT until 20:17:10 UT. A zoom of the emission observed by DEMETER and Chistochina in the Northern hemisphere is shown in Fig. 6. DEMETER in the North sees 2-hop triggered emissions. There are $9 \mathrm{~s}$ between the pulses on DEMETER plot and Chistochina plot. Pulses are elongated with triggered emissions. DEMETER does not see the direct emission as it is in the Chistochina plot because the orbit is not close to HAARP. Nothing is observed in the Juneau plot, although it is just below the DEMETER orbit.

In the Southern hemisphere pulses with triggered emissions are observed at different frequencies starting at 20:43:30 UT until the end of the DEMETER record at 20:46:30 UT (see the orbit in Fig. 7) but it is during survey mode, i.e., without good time and frequency resolution. The frequency pattern generated by HAARP at this time is three 3 -s pulses at $1890 \mathrm{~Hz}, 2370 \mathrm{~Hz}$, and $1710 \mathrm{~Hz}$, followed by one 6-s ramp. Despite the bad resolution, it is possible to see on the DEMETER plot (not shown) that the pulses at $1710 \mathrm{~Hz}$ and $1890 \mathrm{~Hz}$ are accompanied by triggered emissions and that such triggered emissions are absent with the pulses at $2370 \mathrm{~Hz}$. Except the frequency pattern nothing special is observed in the Chistochina plot (not shown). As it was when DEMETER was in the Northern hemisphere, nothing is also observed on the Juneau plot. This case is an important example of ELF/ VLF nonlinear triggering by HAARP that is observed above the ionosphere, but not on the ground. The fact that the emissions are observed in both conjugate hemispheres suggests that the path is ducted at least near the equator. A possible explanation might be that the 


\section{DEMETER}

ICE VLF Spectrogram E12

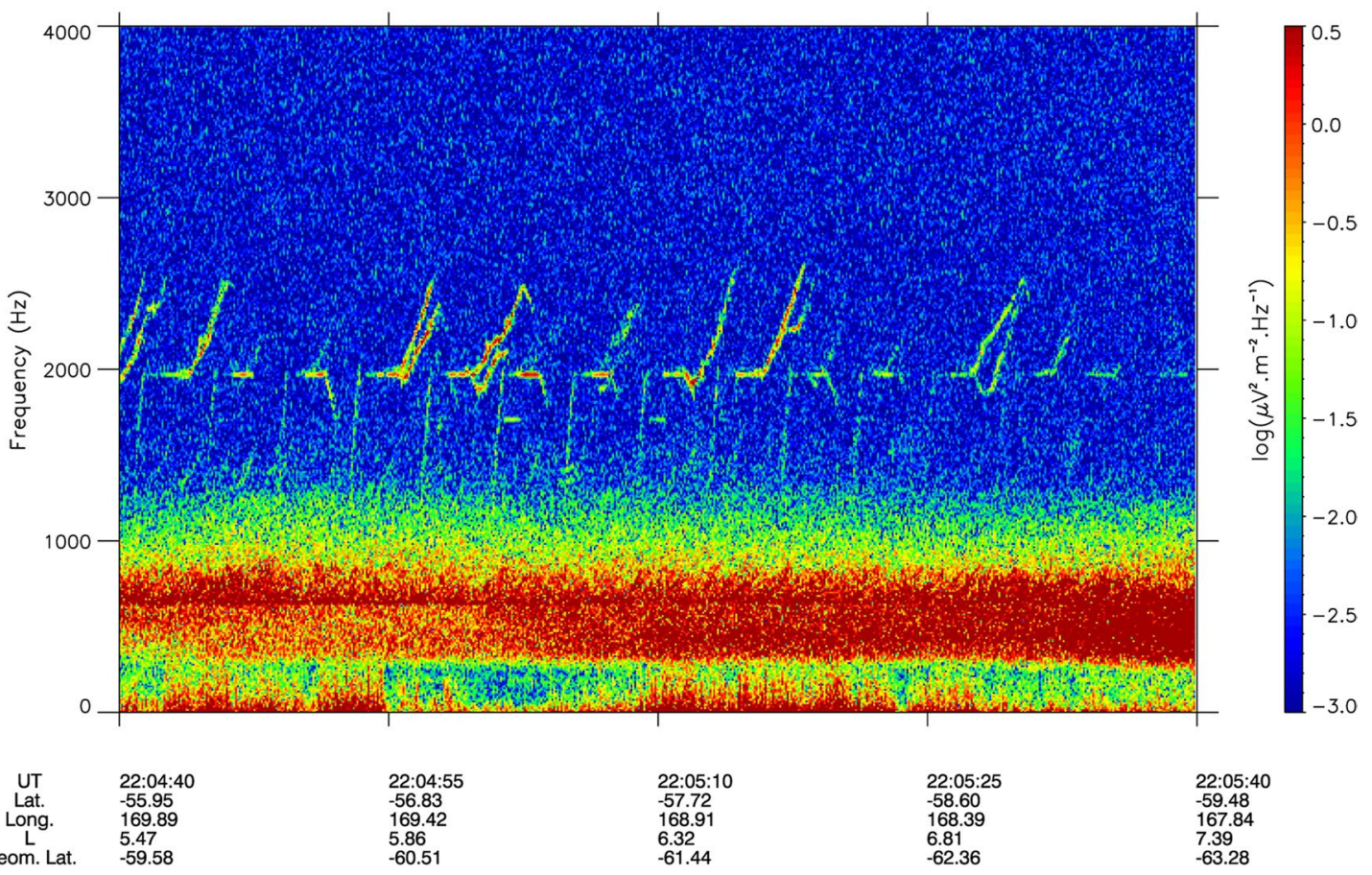

Fig. 2 Spectrogram of an electric component recorded onboard DEMETER in the Southern hemisphere between 22:04:40 and 22:05:40 UT, and in the frequency range $0-4 \mathrm{kHz}$. The power spectral density is color-coded according to the scale on the right. The parameters below the panels indicate the UT, the geographical latitude and longitude, the Mcllwain parameter $L$, and the geomagnetic latitude

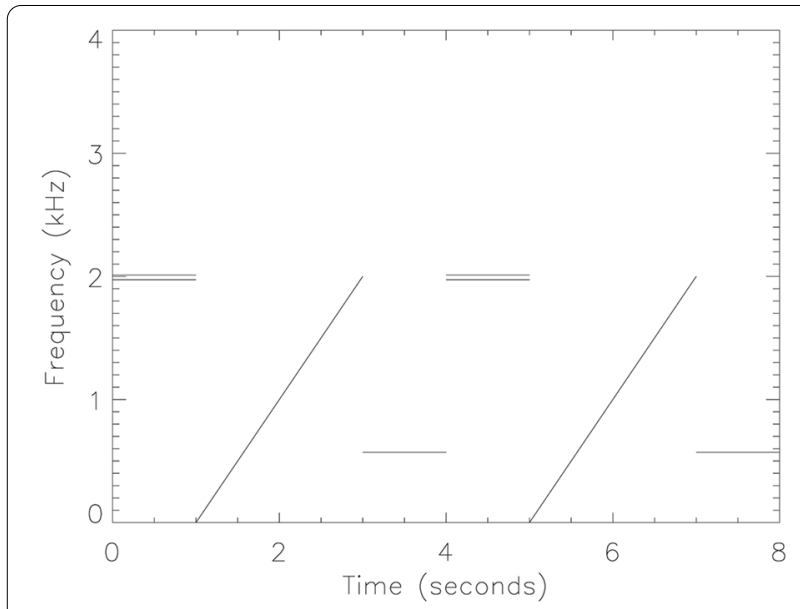

Fig. 3 Pulses and ramp triggered by HAARP during cases 1, 2, and 3

emissions observed by DEMETER propagate in ducts that do not extend below $1000 \mathrm{~km}$ altitude, so that they are reflected from the bottom of the ionosphere and do not reach the ground.

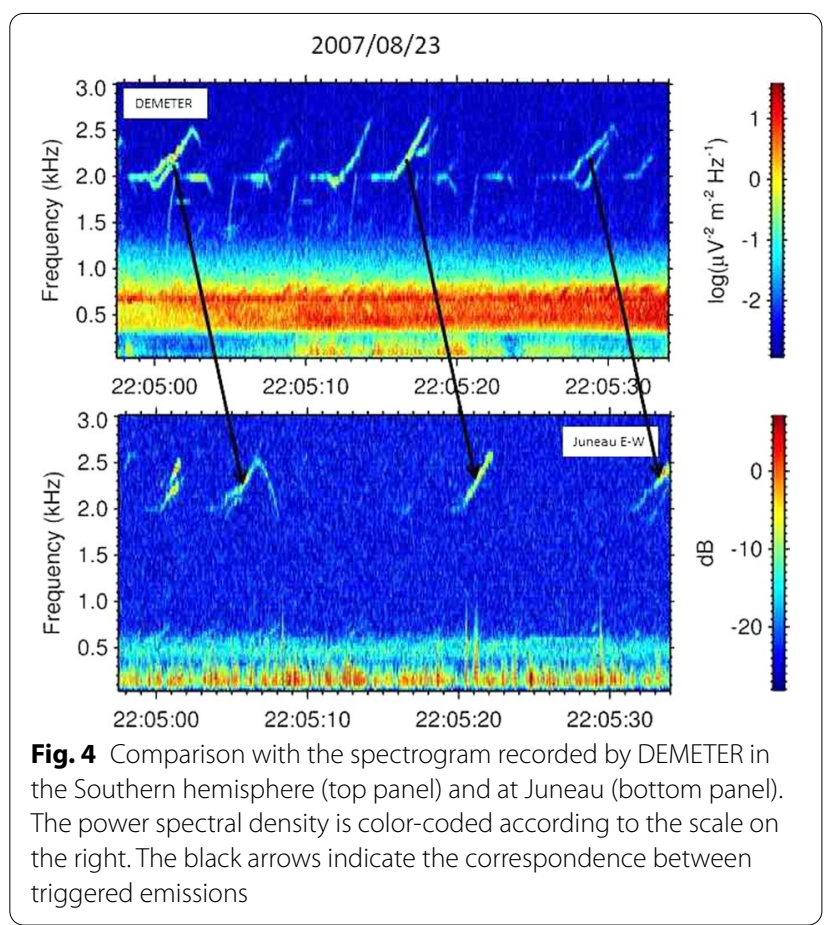




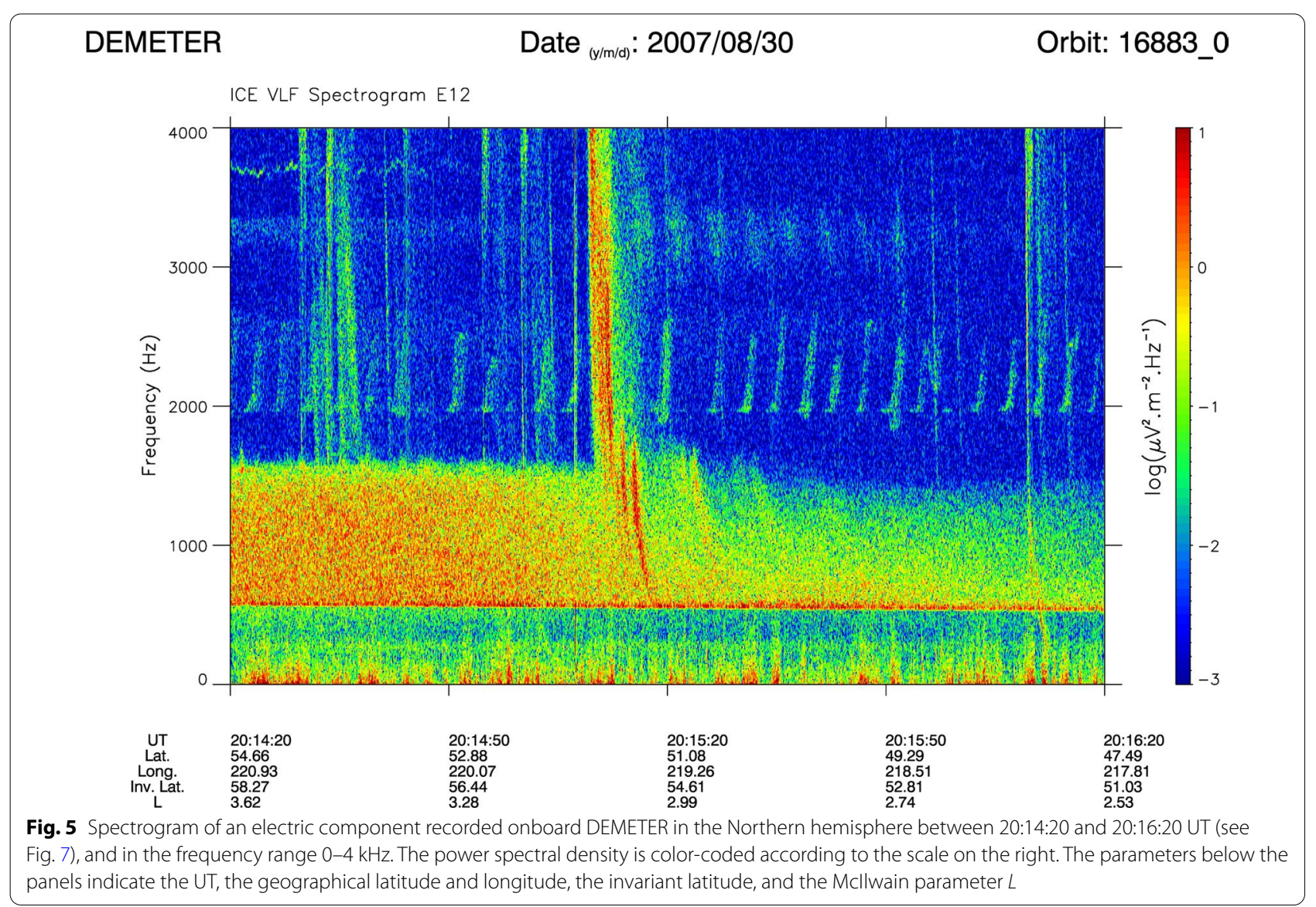

\section{Case 3: 20534_1 2008/05/05 nighttime}

In Fig. 8, the full time interval where magnetospheric emissions are observed by DEMETER in the Southern hemisphere is noticed. It is a nighttime orbit. Figure 9 shows the comparison between the spectrogram recorded by DEMETER in the Southern hemisphere, and the spectrograms recorded by the ground receivers at Chistochina and Juneau. One can see in the top panel (DEMETER spectrogram) a typical MLR event between 1.4 and $1.7 \mathrm{kHz}$. The frequency pattern emitted by HAARP is similar to the one emitted during the case 1 (see Fig. 3). On the Chistochina plot it is possible to see the frequency pattern, whereas on the Juneau plot weak magnetospheric emissions can be observed. A zoom is done in Fig. 10 where an interesting point is discovered. The magnetospheric emissions (falling tones) observed by DEMETER are completely not correlated with the pulses observed at Chistochina at $1713 \mathrm{~Hz}$, although these magnetospheric emissions are around the $1713 \mathrm{~Hz}$ transmitted frequency. There is a time interval of $5.5 \mathrm{~s}$ between each element observed by DEMETER, whereas there is a time interval of $4 \mathrm{~s}$ between each pulse observed by Chistochina. A hypothesis is that one pulse starts to trigger an emission and after this emission becomes a QP emission due to multi-hop. It must be noted that every $44 \mathrm{~s}$ an enhancement could be possible due to the match between one pulse and one QP element. The same QP emissions are also weakly observed on the Juneau plot with a time delay wrt DEMETER of $\sim 3 \mathrm{~s}$ which correspond to a 1-hop travel. It is interesting to notice that only the third harmonic of the pulses at $571 \mathrm{~Hz}$ is able to initiate the emission although we see at Chistochina that the pulses at $1713 \mathrm{~Hz}$ have an intensity less than the $2011 \mathrm{~Hz}$ pulses.

\section{Case 4: 20585_0 2008/05/08 day time}

The DEMETER orbit of this case 4 is shown in Fig. 11. Data are recorded in the Northern hemisphere and in the Southern hemisphere during day time. The spectrogram recorded in the Northern hemisphere is shown in Fig. 12 together with the spectrogram simultaneously recorded at Chistochina. One can see on the DEMETER plot chorus elements at a frequency above $3 \mathrm{kHz}$ around 21:24:30 UT followed by triggered emissions after 21:25:00 UT which corresponds to the closest approach to HAARP. 


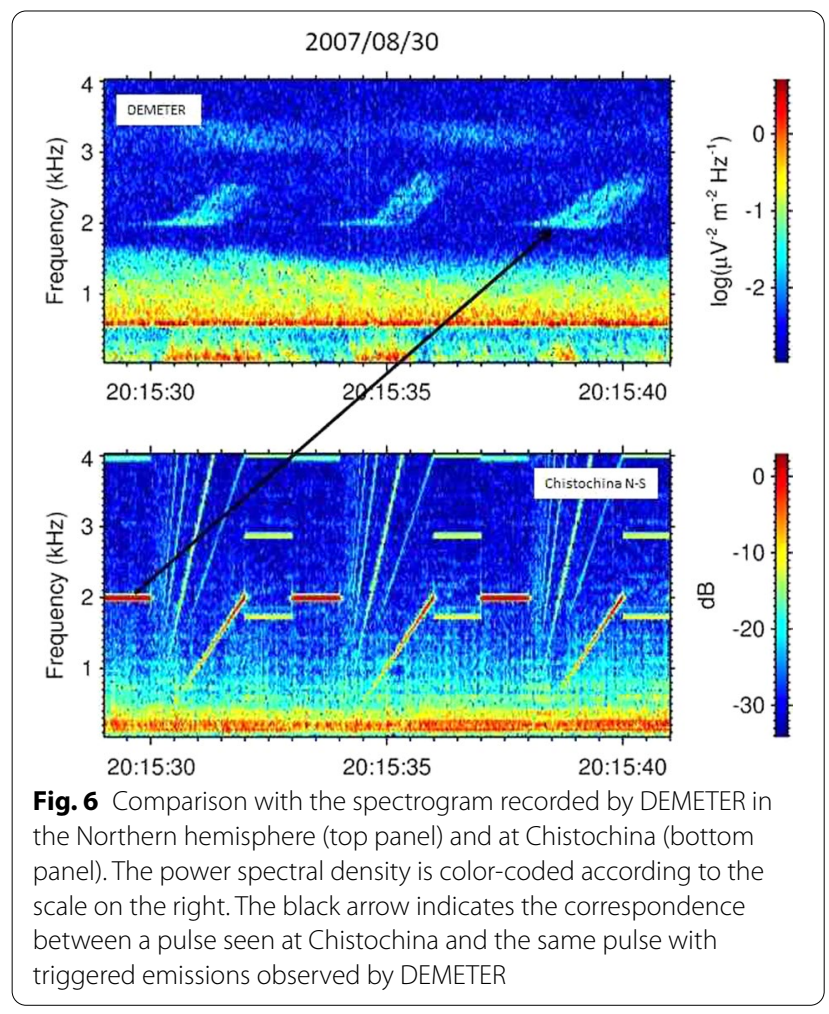

On the contrary, nothing is observed on the Chistochina plot except the pulses.

The frequency pattern of the pulses triggered by HAARP during this time is a repetition of the four 1-s pulses at $500 \mathrm{~Hz}, 3235 \mathrm{~Hz}, 2755 \mathrm{~Hz}$, and $2575 \mathrm{~Hz}$ (see Fig. 13). The pulses at the three last frequencies can be clearly observed in the bottom panel of Fig. 14 together with a harmonic of the $500 \mathrm{~Hz}$ pulse at $4 \mathrm{kHz}$.

In the top panel of Fig. 14 one can see on the DEMETER plot several bursts of triggered emissions. They are around frequencies of the emitted pulses by HAARP at 2575 and $2755 \mathrm{~Hz}$, but their period is slightly different. One can notice that the set of pulses at $3235 \mathrm{~Hz}$ has no influence although they have intensity similar to the pulses at 2575 and $2755 \mathrm{~Hz}$.

When DEMETER is in the southern hemisphere, the corresponding spectrogram is displayed in Fig. 15 together with the spectrogram simultaneously recorded at Chistochina in the North. An important MLR event is observed on the DEMETER plot between 2 and $3 \mathrm{kHz}$, whereas only a weak emission is observed at Chistochina around the same frequencies.

The frequency pattern of the pulses triggered by HAARP during this time has been changed and now we have three 3-s pulses at $2555 \mathrm{~Hz}, 3035 \mathrm{~Hz}$ and $2375 \mathrm{~Hz}$, followed by a ramp during $6 \mathrm{~s}$ (see Fig. 16). This can be seen in the bottom panel of Fig. 17 which is a zoom of

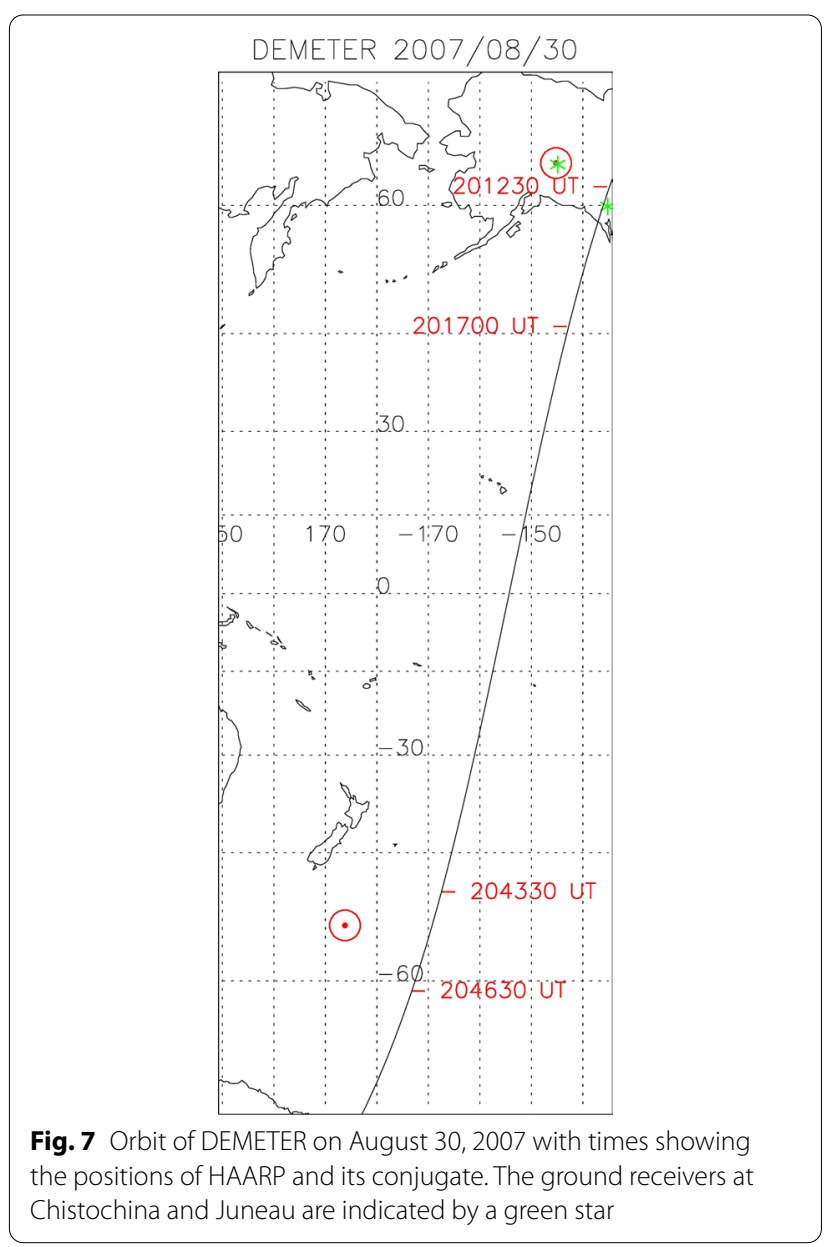

Fig. 15. We see in Fig. 17 the same bursts of triggered emissions on DEMETER and at Chistochina with a delay of $4 \mathrm{~s}$ because Chistochina sees the 2-hop emissions, whereas DEMETER sees the 1-hop emissions. But here also it is difficult to have a match between a pulse and a burst of triggered emissions although all these bursts of triggered emissions seen by DEMETER and Chistochina seem to be due to the two series of pulses at $2375 \mathrm{~Hz}$ and $2555 \mathrm{~Hz}$. Once again nothing is seen for the set of pulses at $3035 \mathrm{~Hz}$. As it has been observed before it seems that there is no more amplification in the second equatorial crossing for the triggered emissions which return in the Northern hemisphere and are seen by Chistochina.

\section{Case 5: 20614_0: 2008/05/10 day time}

This is an example of MLR recorded onboard DEMETER along the half-orbit shown in Fig. 18 during day time. Spectrograms recorded by DEMETER in survey mode in the Northern hemisphere as well as in the Southern hemisphere are shown in Fig. 19. These spectrograms exhibit in the North and in the South clear MLR between 1.3 and $2.3 \mathrm{kHz}$. In the North one can 


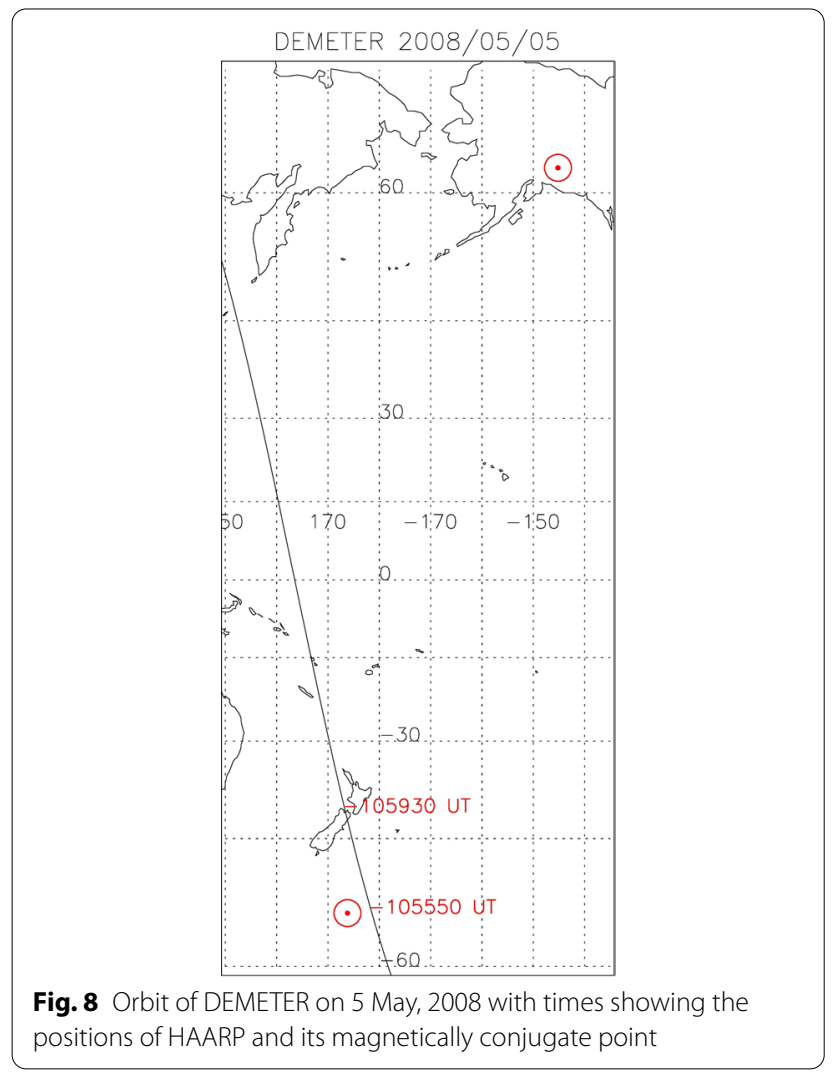

even see two distinct MLR events around $1.5 \mathrm{kHz}$ and around $2 \mathrm{kHz}$. It can be seen in Fig. 18 that these MLR are recorded close to HAARP and its conjugate point.

Ground data have been recorded at Juneau during the same day. The corresponding spectrogram is shown in Fig. 20 between 20:46:00 and 21:30:00 UT in the frequency range $0-4 \mathrm{kHz}$. One can also see a similar MLR event around $2 \mathrm{kHz}$. The time intervals delimitated by double arrows indicate when DEMETER has simultaneously registered data in burst mode. A comparison between the spectrograms recorded by DEMETER in the Northern hemisphere, at Chistochina, and at Juneau is done in Fig. 21. Juneau sees exactly the same elements as DEMETER except the chorus event around $1 \mathrm{kHz}$ but we see these chorus elements very weak on the Chistochina plot. This Chistochina plot also displays the set of pulses and ramps generated by HAARP. Every minute the frequency pattern is the following: five times there are three $2 \mathrm{~s}$ pulses at $1110 \mathrm{~Hz}$, $1525 \mathrm{~Hz}$, and $2125 \mathrm{~Hz}$, followed by three $10 \mathrm{~s}$ ramps (see Fig. 22). Then the interval between 2 pulses at the same frequency is $4 \mathrm{~s}$ which means that every $6 \mathrm{~s}$ there is a pulse at this frequency followed by a gap during $34 \mathrm{~s}$. Six seconds is close to a 2-hop travel and this is important for our observation. Between each set of

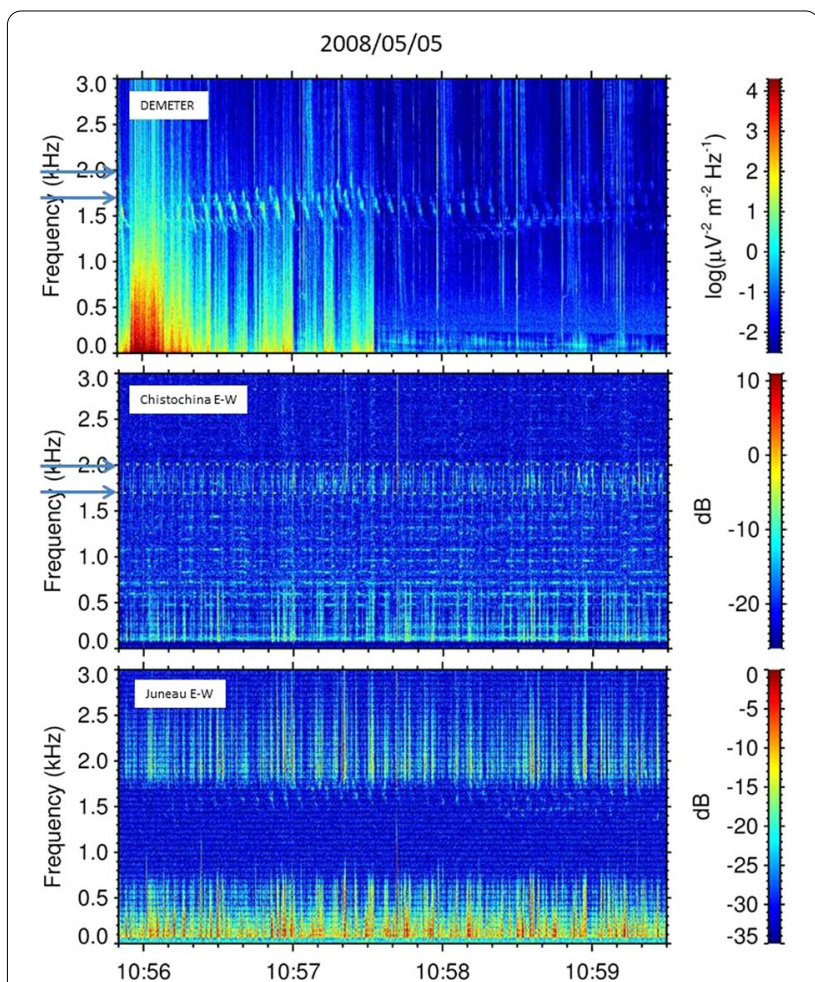

Fig. 9 Spectrograms recorded onboard DEMETER (top panel), at Chistochina (middle panel), and at Juneau (bottom panel) between 10:55:50 and 10:59:30 UT in the frequency range $0-3 \mathrm{kHz}$. The power spectral density is color-coded according to the scale on the right

5 pulses there is a set of 3 ramps, the last one being a snake ramp.

A zoom of Fig. 21 is shown in Fig. 23. It appears now that there is a combination of two different sets of QP emissions which are inserted. One can see on the Chistochina plot 3 set of pulses at $1525 \mathrm{~Hz}, 2125 \mathrm{~Hz}$, and $2220 \mathrm{~Hz}$ (it is in fact harmonics of the pulses at $1110 \mathrm{~Hz}$ ). But on the DEMETER plot, we do not see all these pulses. Only the pulses at $2125 \mathrm{~Hz}$ seem to play a role in the triggered emissions as it corresponds to the higher frequency of the QP elements noted by red arrows. We only see 3 pulses at $2125 \mathrm{~Hz}$ and after they disappear. In fact we only see the pulses at a specific location when DEMETER is at the closest approach to HAARP (see Fig. 18). Even if it is weak, the fourth pulse of this series at $2125 \mathrm{~Hz}$ overlaps in fact with one element of the QP emissions noted by arrows. We see after an increase of these QP elements which are going back and forth in the magnetosphere. These QP elements are of dispersive type (negative slope) with lines at the lower frequencies. A rough estimation of the time interval between these QP emissions (noted by red arrows) is $6.3 \mathrm{~s}$ which corresponds to a 2-hop travel. The point is that it is close to the time interval between 2 pulses which is $6 \mathrm{~s}$. This means that, at the beginning, the 


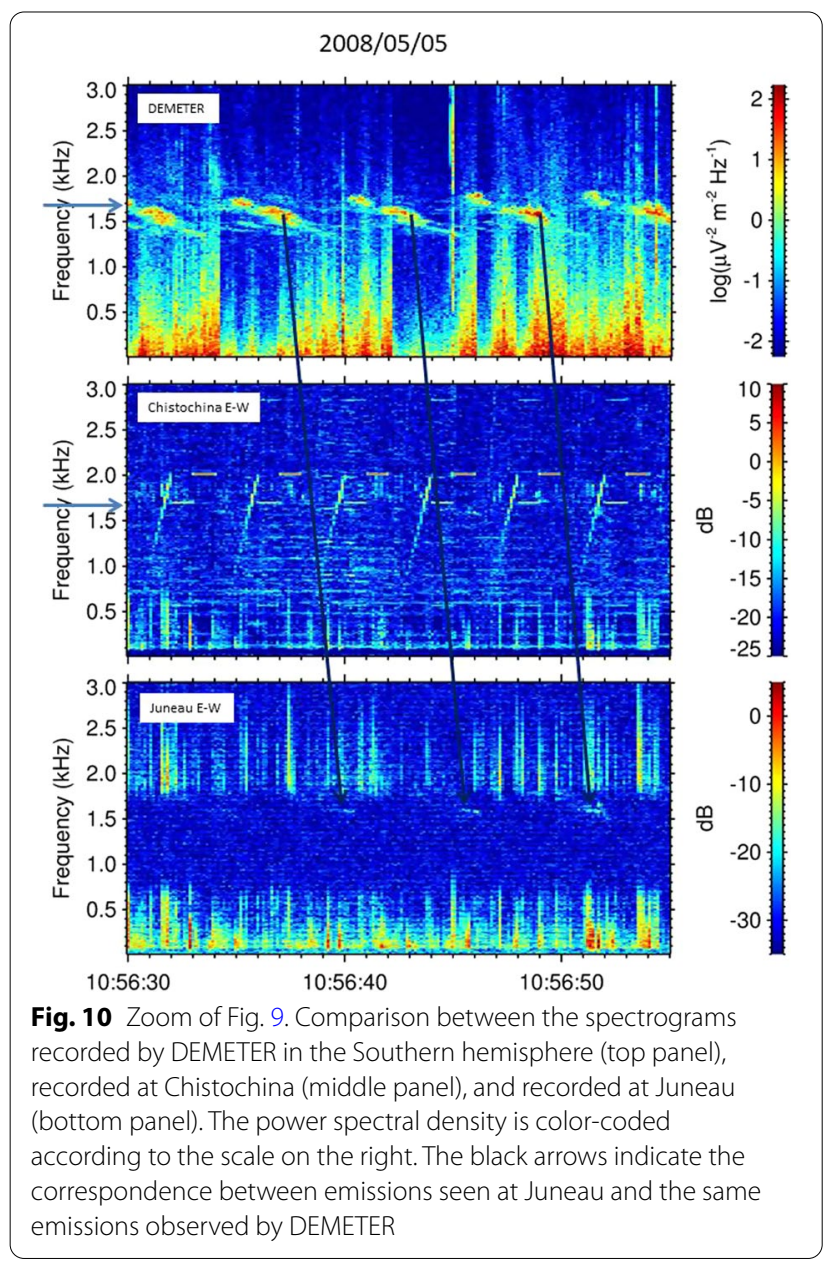

first QP elements could have been enhanced by a previous set of pulses. These QP structures indicated by red arrows are in the form of inverse commas with increasing frequency dispersion as the time is going on. The intense triggering emissions at 20:48:25 UT start to occur when a low frequency part of one element of these QP structures overlaps with one of the elements indicated by the black arrows. These elements are formed by a ramp previously emitted which is amplified at the equator and which bounces between hemispheres with a period of $\sim 11 \mathrm{~s}$. It is very likely that it is due to the snake ramp as Gołkowski et al. (2008) found that a snake ramp can exhibit clear repeatable magnetospheric amplification and inter-hemisphere propagation even though other signals in the same frequency range were transmitted. At the end a second set of QP elements is formed. Juneau sees the same two sets of QP elements as DEMETER at the same time but does not see the parent emissions triggered by HAARP (pulses and ramps) that we have on the Chistochina plot.

Later on, in the zoom of Fig. 24 we see on the DEMETER plot pulses between QP emissions but they do not

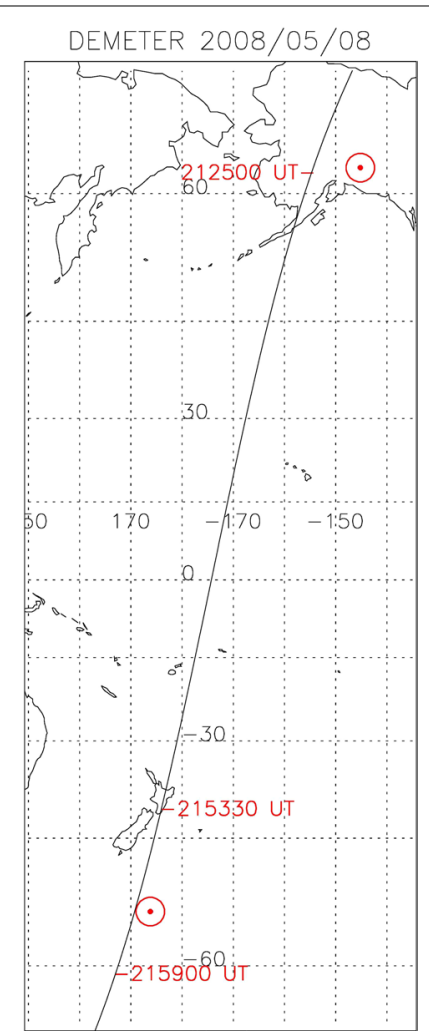

Fig. 11 Orbit of DEMETER on 8 May, 2008 with times showing the positions of HAARP and its magnetically conjugate point

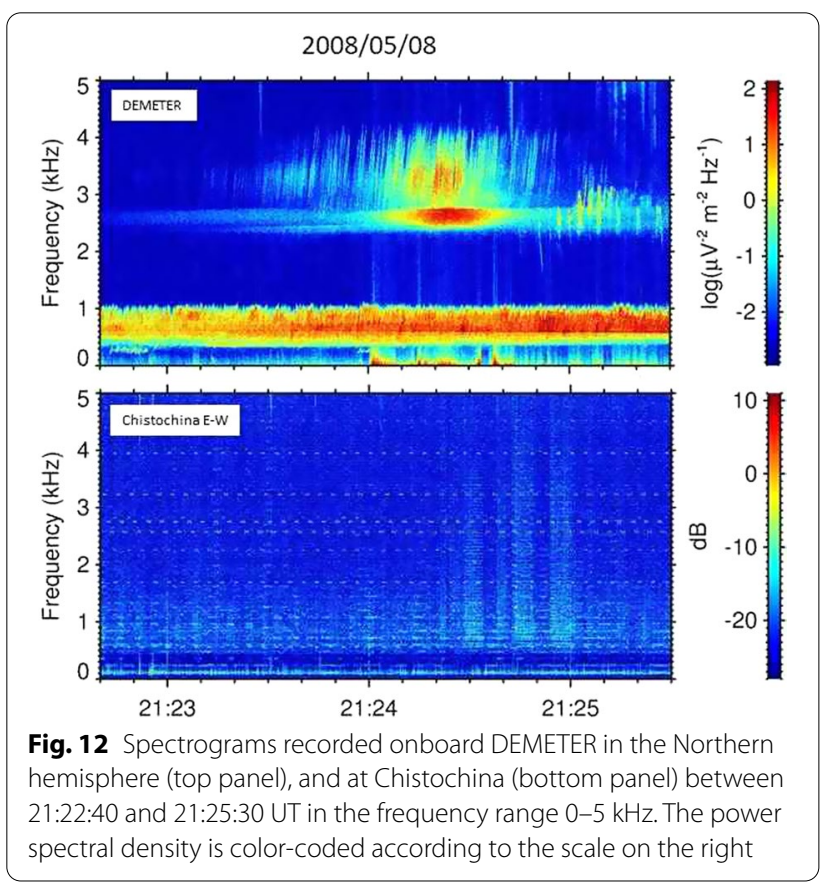




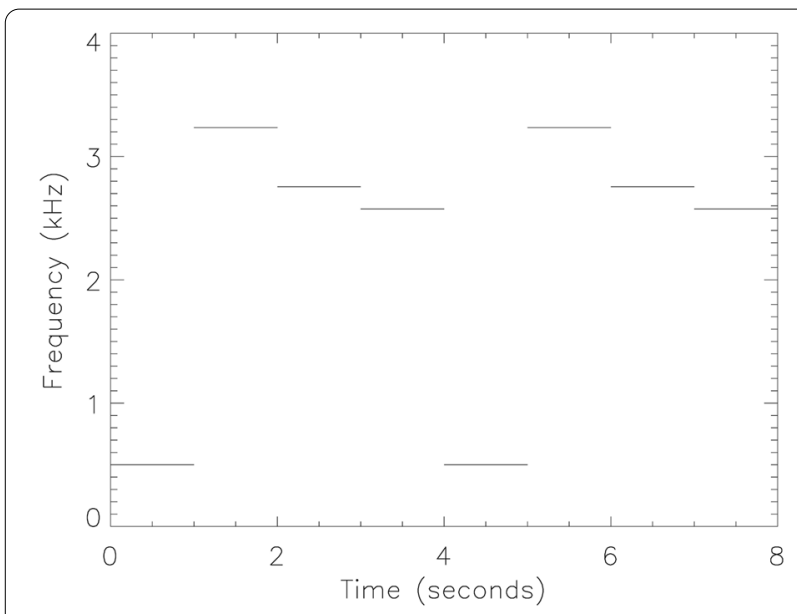

Fig. 13 Pulses triggered by HAARP during the case 4 when DEMETER is in the Northern hemisphere

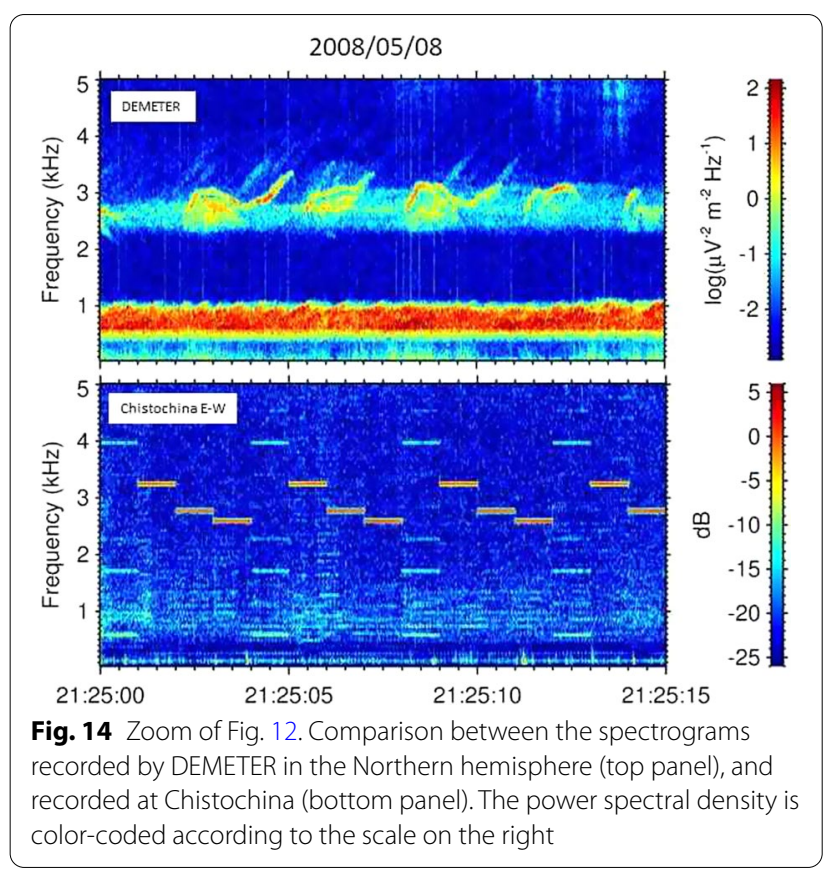

exactly correspond to the pulses seen by Chistochina at the same time because DEMETER is too far to observe the direct pulses. It could be 2-hop emissions generated by previous pulses because we see them even when there is a gap during which ramps are sent, or it is another QP emission which could be reinforced when they match the pulses as we said before.

In the plots in Figs. 23 and 24, there are additional sidebands (and/or spectral broadening) as far as multihops are going on. But only upper side bands seem to be triggered. For these QP elements there is a frequency

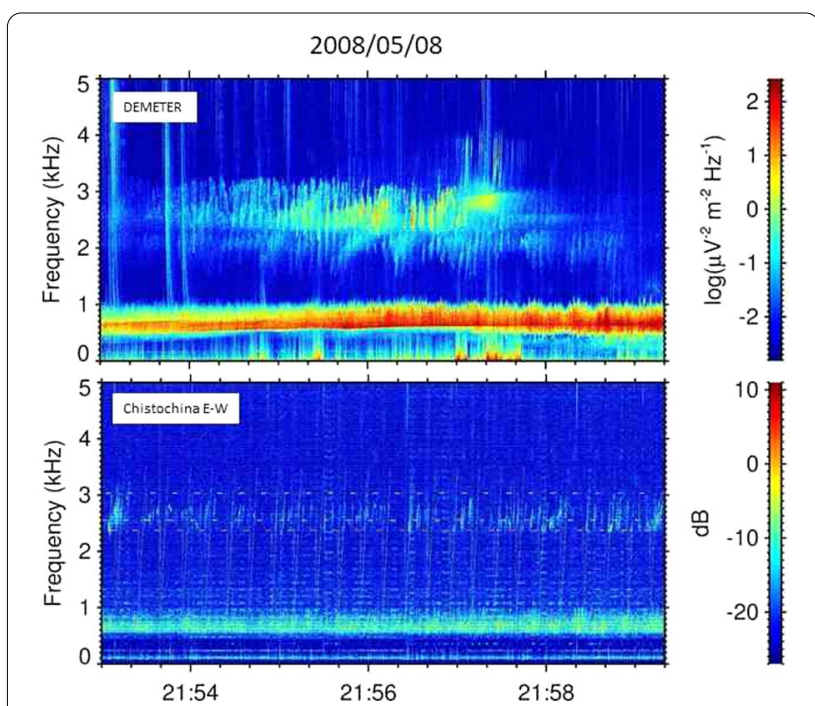

Fig. 15 Spectrograms recorded onboard DEMETER in the Southern hemisphere (top panel), and at Chistochina (bottom panel) between 21:53:00 and 21:59:20 UT in the frequency range $0-5 \mathrm{kHz}$. The power spectral density is color-coded according to the scale on the right

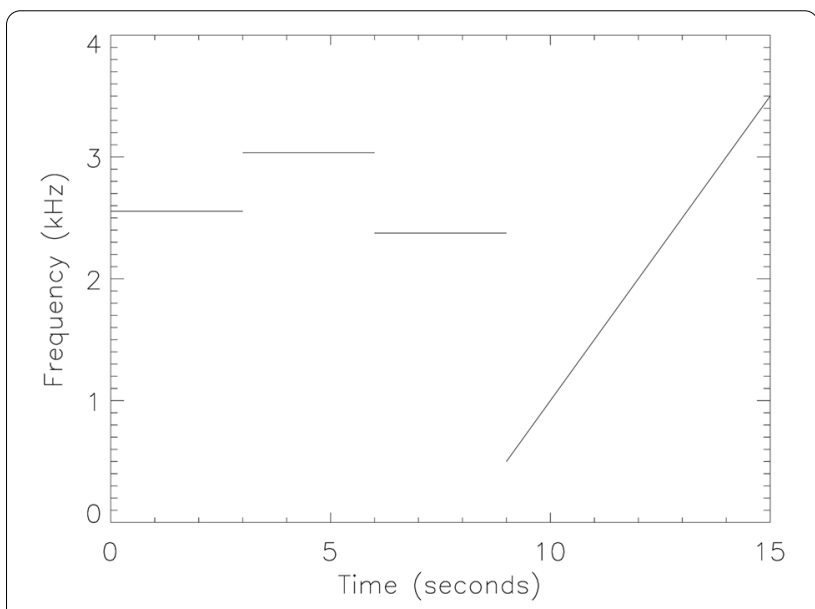

Fig. 16 Pulses and ramp triggered by HAARP during the case 4 when DEMETER is in the Southern hemisphere

dispersion when the number of hops is increasing as it is for the whistlers.

It must be noted that the second MLR event between 1.5 and $1.8 \mathrm{kHz}$ seen in Figs. 19 and 21 on the DEMETER plot is also observed on the Juneau plot but with a lower intensity. This distinct MLR event at lower frequency can be caused by the pulses at $1525 \mathrm{~Hz}$ as it was discussed above.

Figure 25 displays a spectrogram from DEMETER which is now in the South hemisphere (top panel), a spectrogram from Chistochina (middle panel), and a spectrogram from Juneau (bottom panel). A similar MLR 


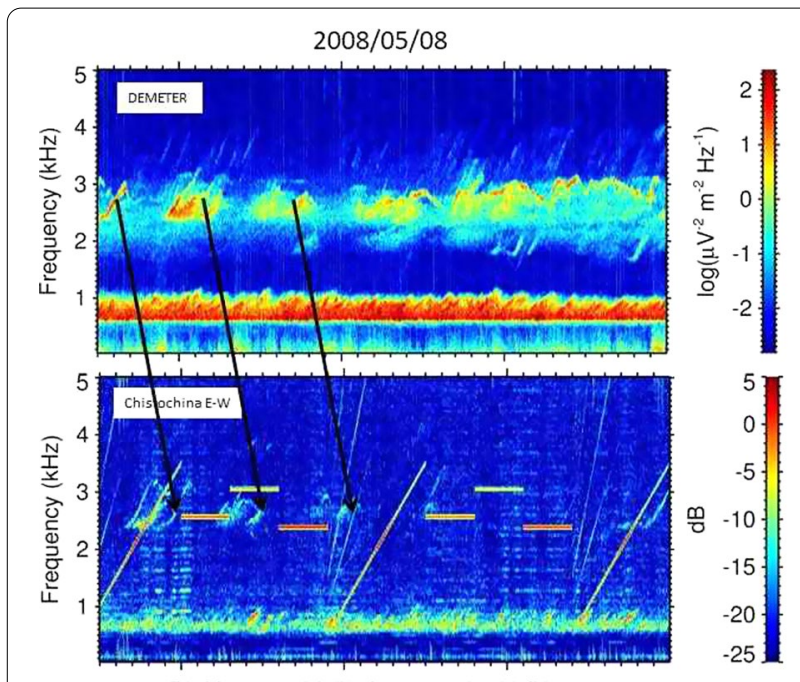

21:56:30

21:56:40

21:56:50

Fig. 17 Zoom of Fig. 15. Comparison between the spectrograms recorded by DEMETER in the Southern hemisphere (top panel), and recorded at Chistochina (bottom panel). The power spectral density is color-coded according to the scale on the right. The black arrows indicate the correspondence between bursts of triggered emissions seen at Chistochina and the same bursts of triggered emissions observed by DEMETER event is clearly observed in the DEMETER and Juneau plots. As it is seen in Fig. 20, it is the same event formed by QP elements which continues. The event is triggered at the beginning with the help of HAARP pulses and ramps, and it continues without other relation with the pulses observed on the Chistochina plot. This is confirmed by a change of the frequency pattern between 20:58:00 and 21:09:30 UT. It becomes three $3 \mathrm{~s}$ pulses at $755 \mathrm{~Hz}, 935 \mathrm{~Hz}$, and $1415 \mathrm{~Hz}$ followed by a $6 \mathrm{~s}$ ramp (after 21:10:00 UT it returns to the previous one). No difference appears in the event during this time interval (see Fig. 20).

Figure 26 presents a zoom of Fig. 25. The time interval between each QP elements in the top panel of Fig. 26 is $6.24 \mathrm{~s}$ corresponding to 2-hop. The time delay between DEMETER and Juneau QP elements is of the order of $3.1 \mathrm{~s}$.

\section{Propagation analysis of single-frequency signals (case 6)}

ELF/VLF emissions triggered by HAARP on April 5, 2010 and recorded by the satellite along the orbit shown in Fig. 27 are displayed in the top panel of Fig. 28 which

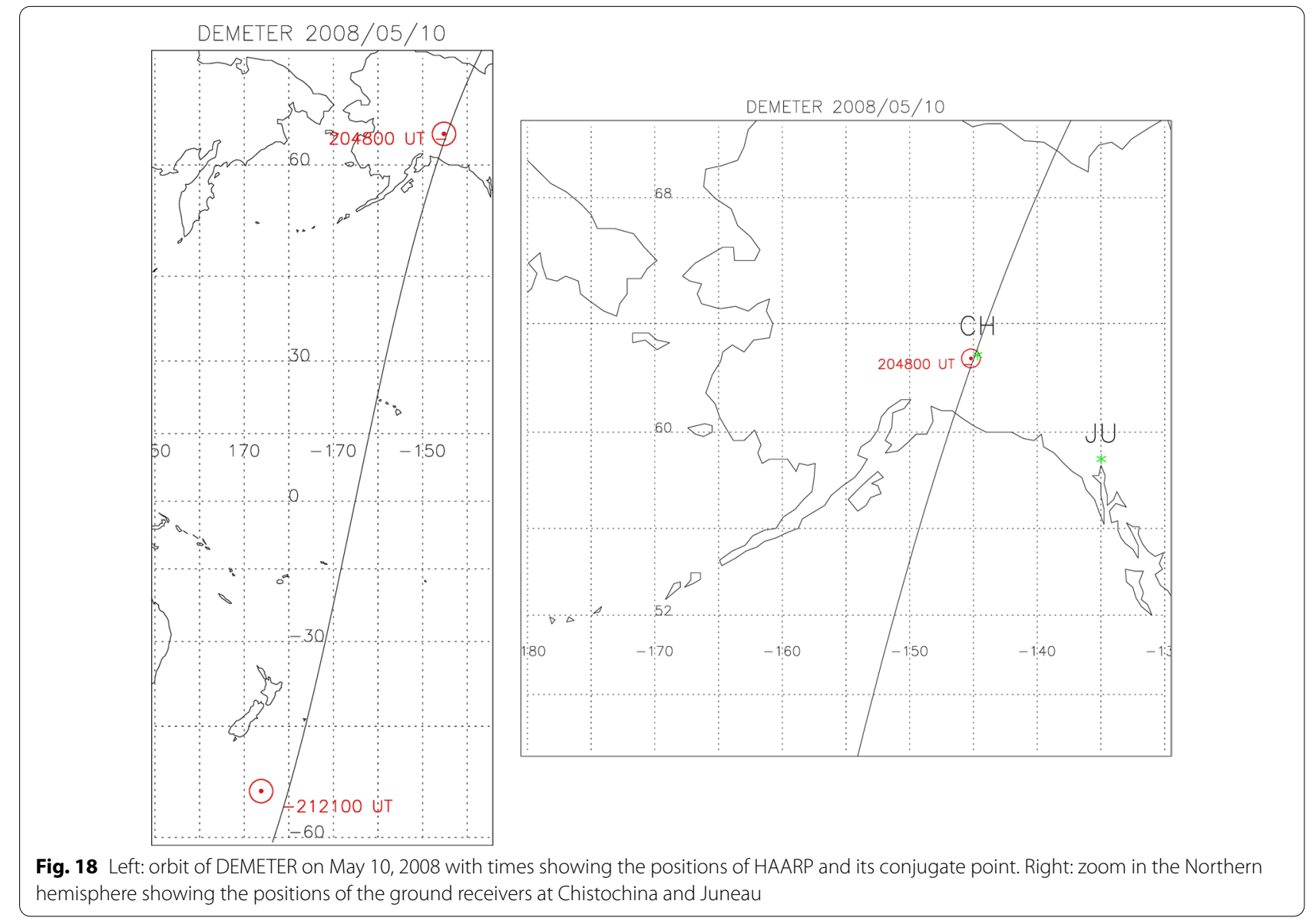




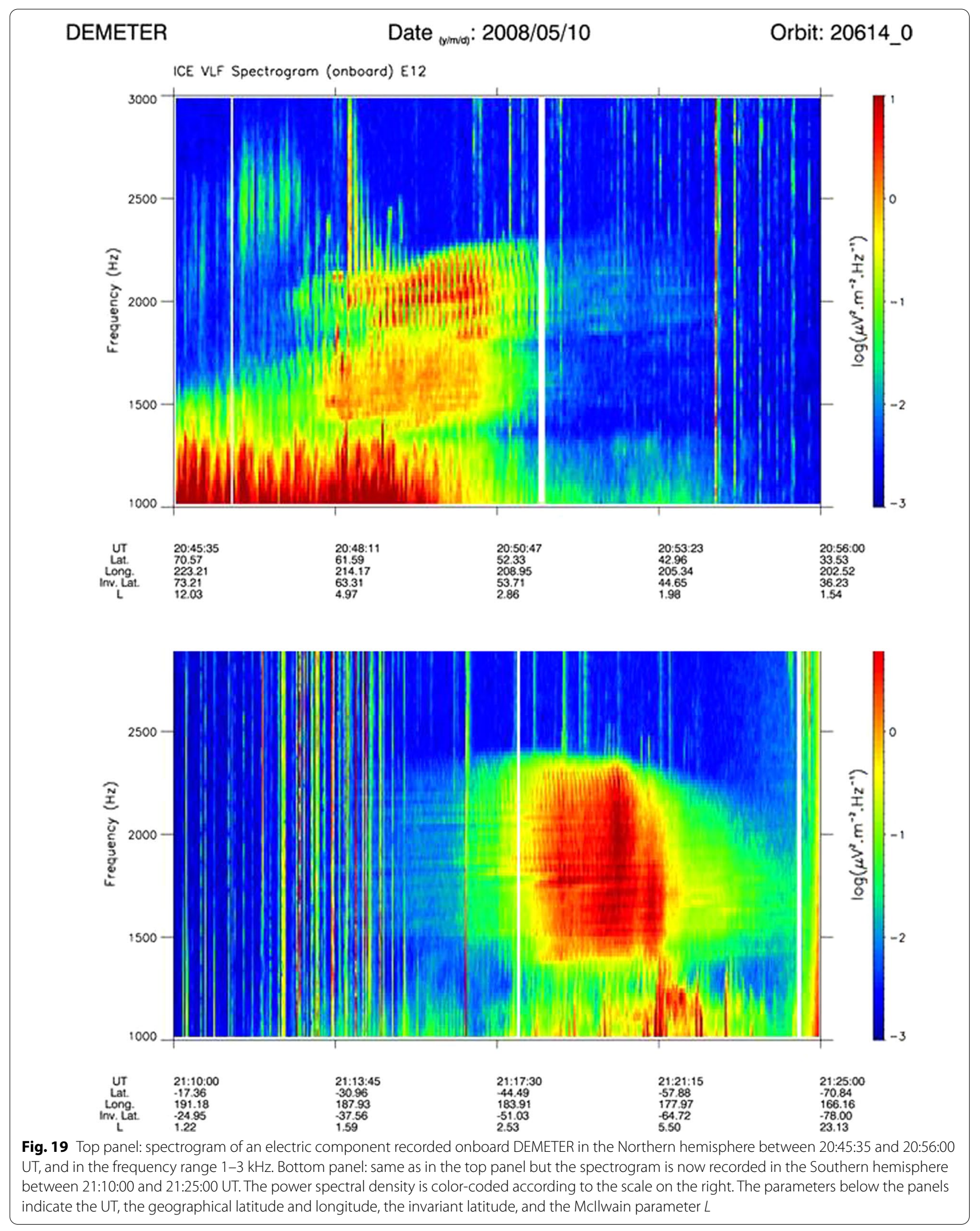




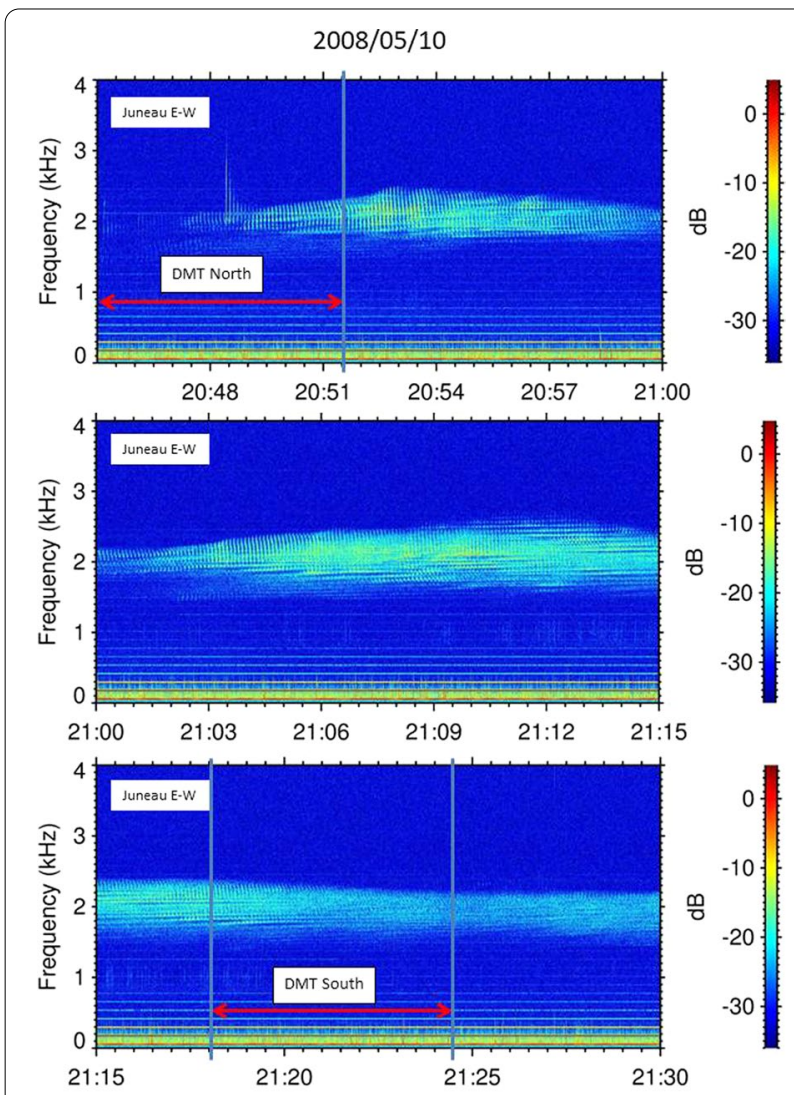

Fig. 20 Spectrogram recorded at Juneau on May 10, 2008 between 20:46:00 and 21:30:00 UT in the frequency range $0-4 \mathrm{kHz}$. The power spectral density is color-coded according to the scale on the right. The red double arrows indicate the time intervals when DEMETER data are simultaneously present in burst mode in the Northern and in the Southern hemisphere

presents the spectrogram of an electric field component between 0 and $5 \mathrm{kHz}$. The HAARP frequency pattern is a 3-s pulse at $520.8 \mathrm{~Hz}$ followed by a 3-s pulse at $2083 \mathrm{~Hz}$. In addition to these pulses at $520.8 \mathrm{~Hz}$ and $2083 \mathrm{~Hz}$, one can see in the plot several series of pulses which correspond to harmonics. Intense electrostatic turbulence is also observed between 06:29:37 and 06:30:12 UT. It corresponds to a dramatic depletion of the electron density which is exhibited in the bottom panel of Fig. 28. This electron density depletion is known as the ionospheric trough which is very often observed at the latitude of HAARP (Piddyachiy et al. 2011). It can be noted in the spectrogram that there is a strong spectral broadening of the pulses at two specific frequencies $(2083 \mathrm{~Hz}$ and $4166 \mathrm{~Hz}$ ) due to the interaction with the electrostatic turbulence.

It is possible to determine the propagation characteristics of the two set of pulses observed at frequencies lower than $1.25 \mathrm{kHz}$ in the top panel of Fig. 28 because the six
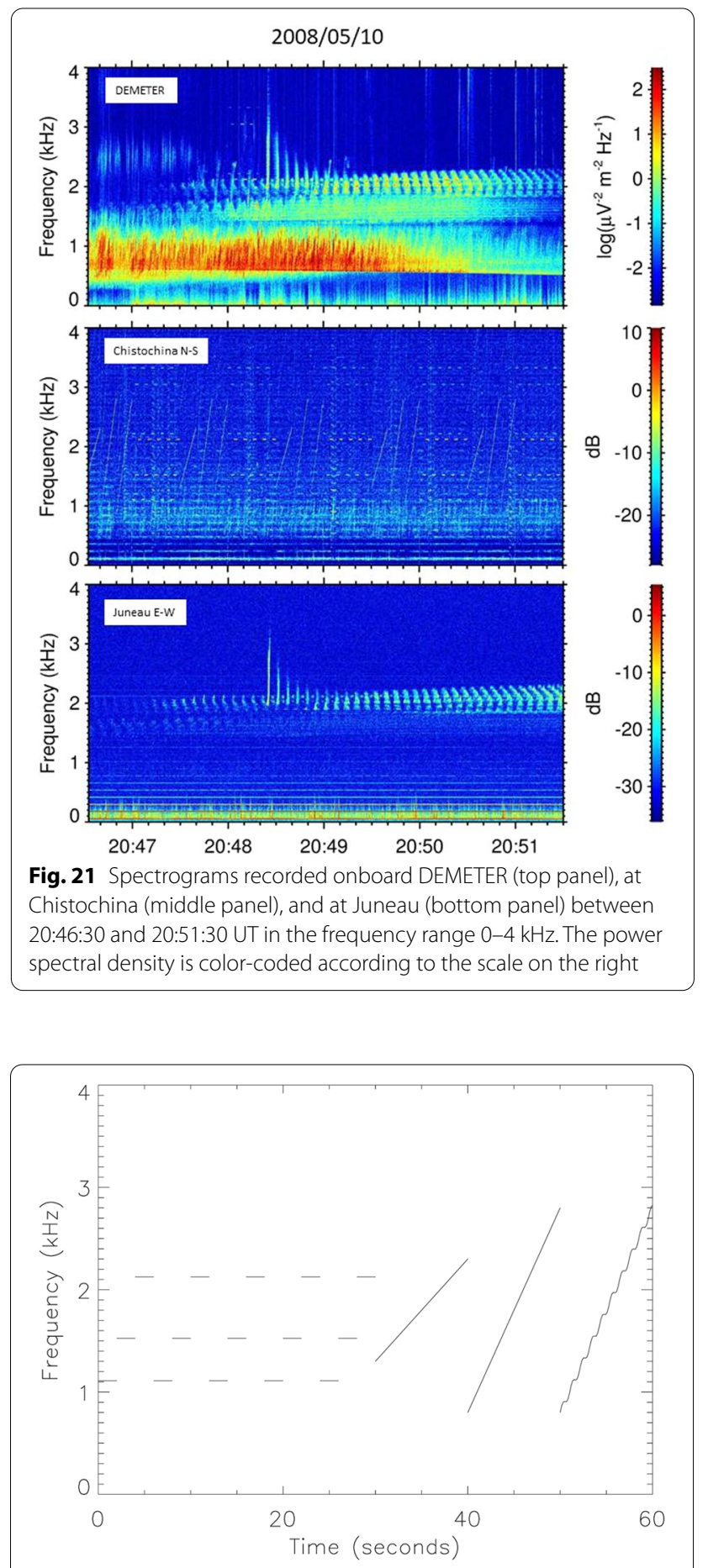

Fig. 22 Pulses and ramps triggered by HAARP during the case 5

components of the electromagnetic field are available in burst mode (see above the section about DEMETER). Figure 29 shows the wave propagation analysis of these two set of pulses. Frequency-time spectrograms of the magnetic and electric field fluctuations are shown in the 


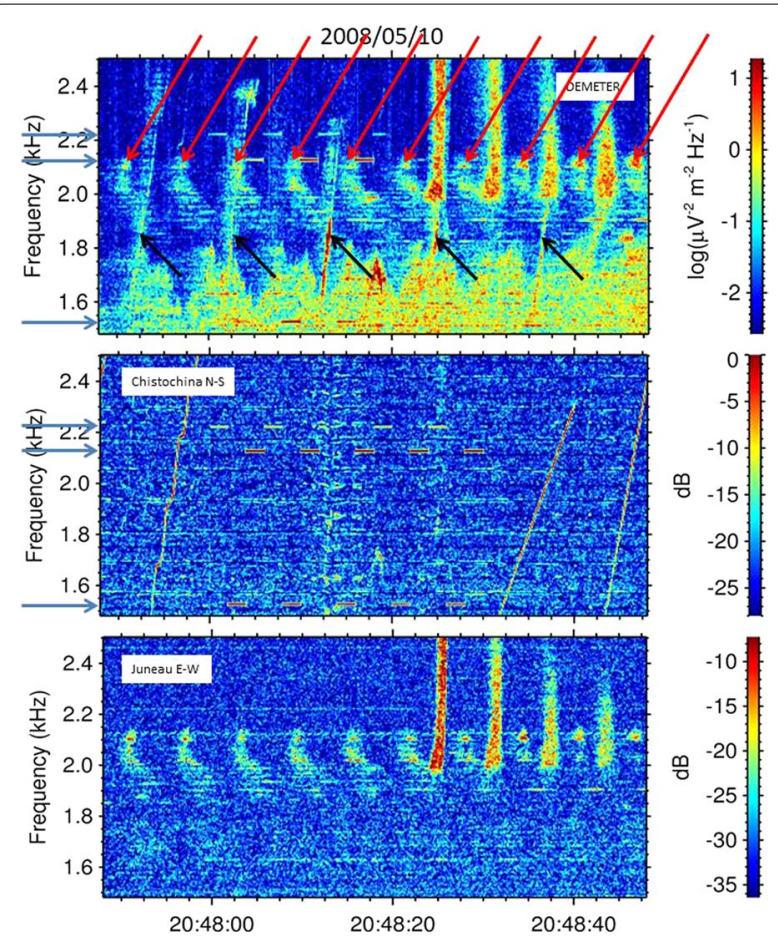

Fig. 23 Zoom of Fig. 21 showing data between 20:47:48 and 20:48:48 UT in the frequency range $1.5-2.5 \mathrm{kHz}$. The power spectral density is color-coded according to the scale on the right

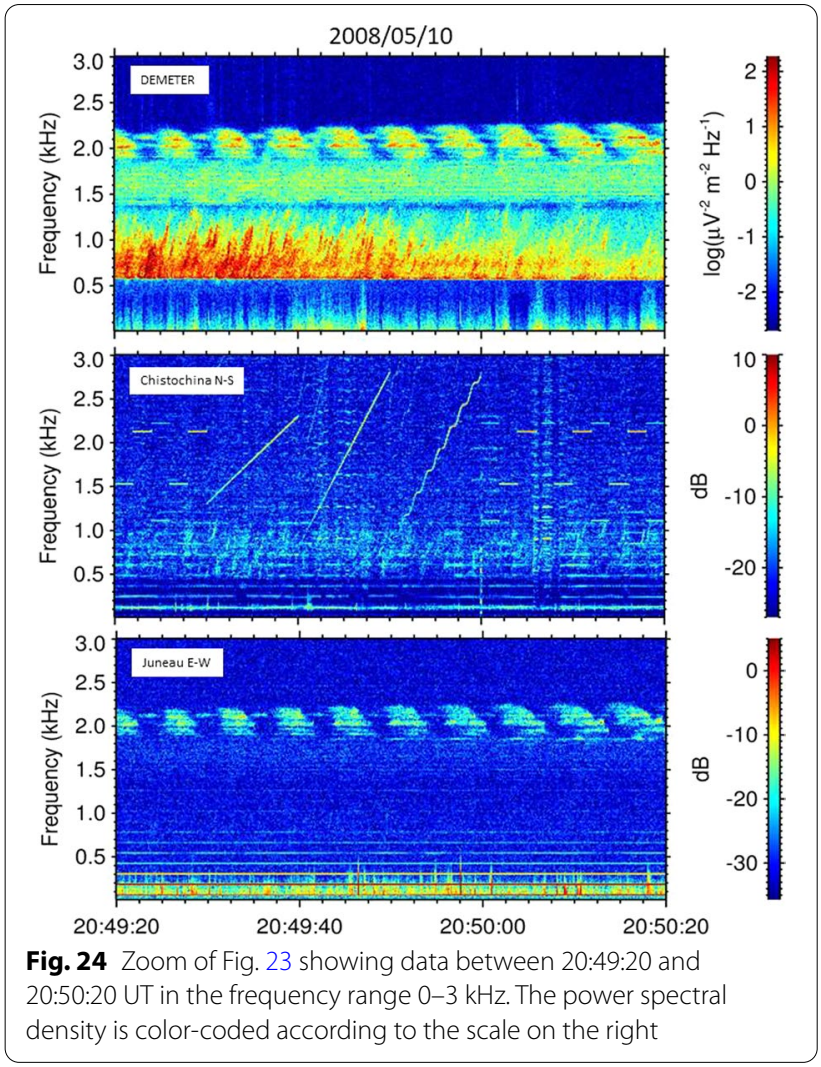

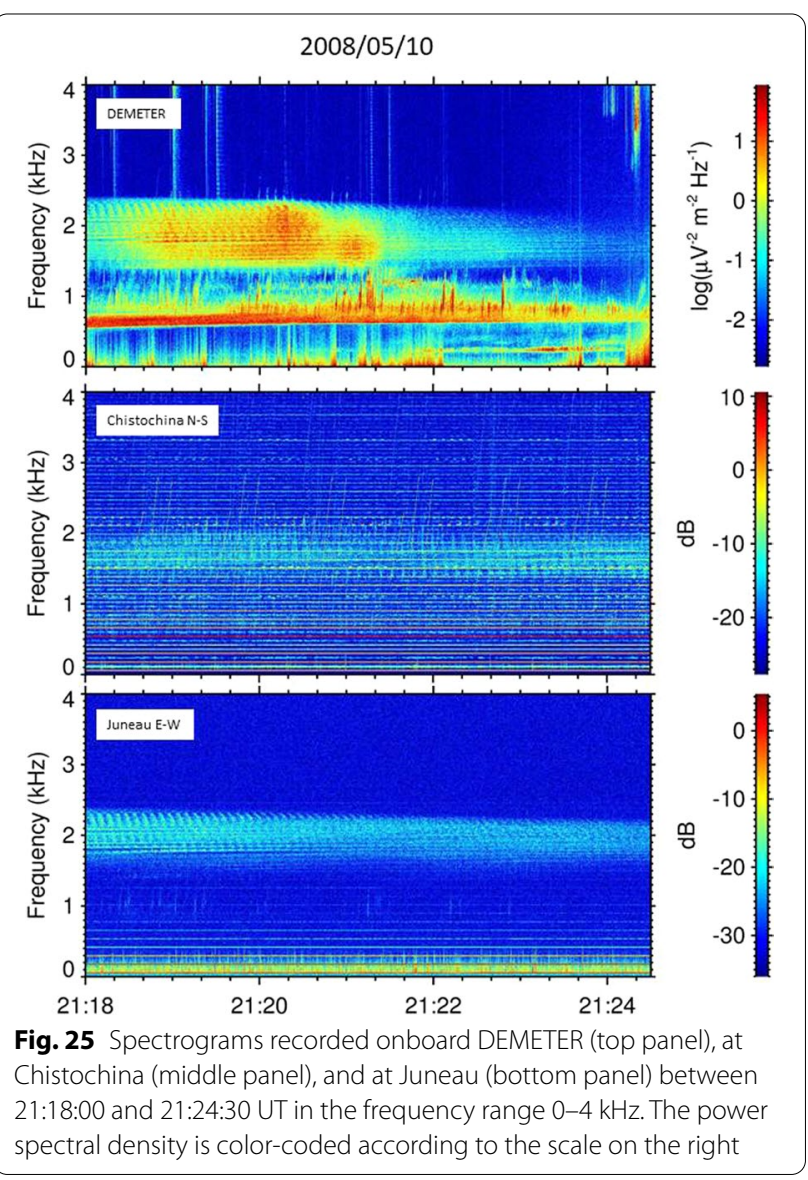

first two panels. The third panel represents the ellipticity $E_{\mathrm{B}}$ (ratio of the axes of the polarization ellipse) obtained using a Singular Value Decomposition (SVD) method (Santolík et al. 2003). The sign of $E_{\mathrm{B}}$ represents the information about the sense of polarization with respect to the stationary magnetic field: negative values are used for left-handed polarization sense and positive values for the right-handed polarization sense. The SVD method is also used to calculate the direction of the wave vector. The fourth panel shows the wave-normal angle $\theta$ defined as the angle between the Earth's magnetic field B and the wave vector. The bottom panel gives the Poynting vector component along the terrestrial magnetic field normalized by its standard deviation resulting from the statistical errors of the spectral analysis (Santolík et al. 2001).

The empty areas in the panels correspond to frequency-time intervals with magnetic power spectral densities less than $10^{-7} \mathrm{nT}^{2} \mathrm{~Hz}^{-1}$. These areas are empty because the analysis is not meaningful for low-power waves.

The results of this multidimensional analysis of plasma wave measurements as a function of the universal time (UT) and frequency indicate that the pulses are 

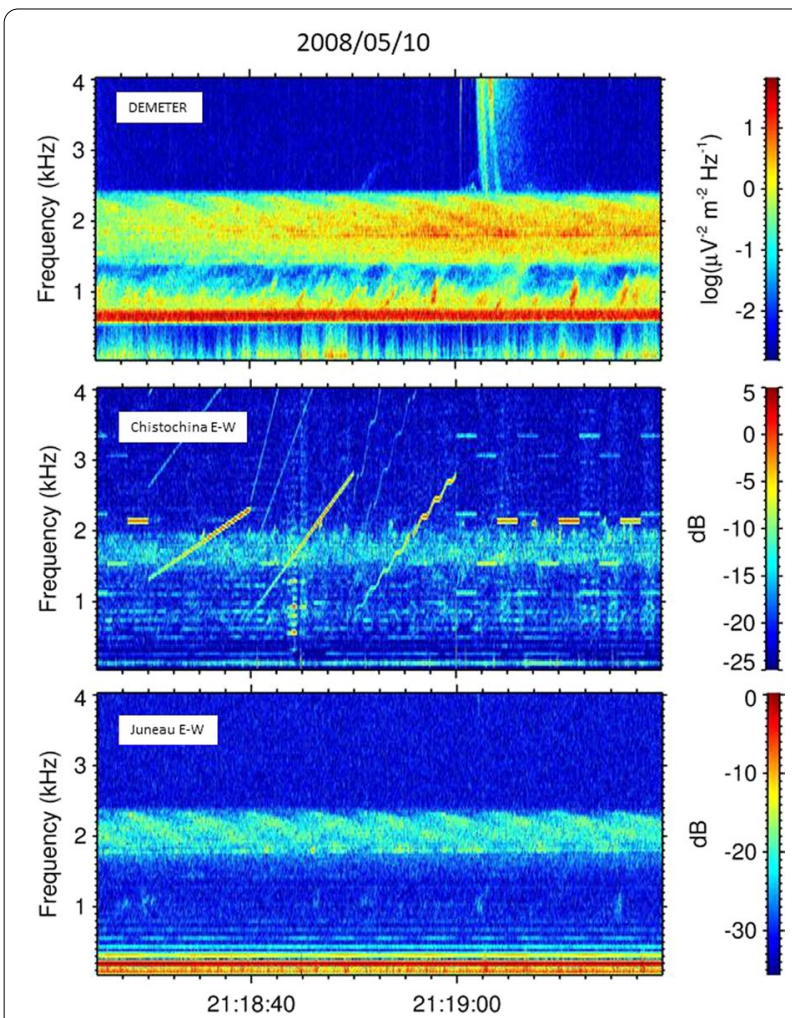

Fig. 26 Zoom of Fig. 25 between 21:18:25 and 21:19:20 UT in the frequency range $0-4 \mathrm{kHz}$. The power spectral density is color-coded according to the scale on the right

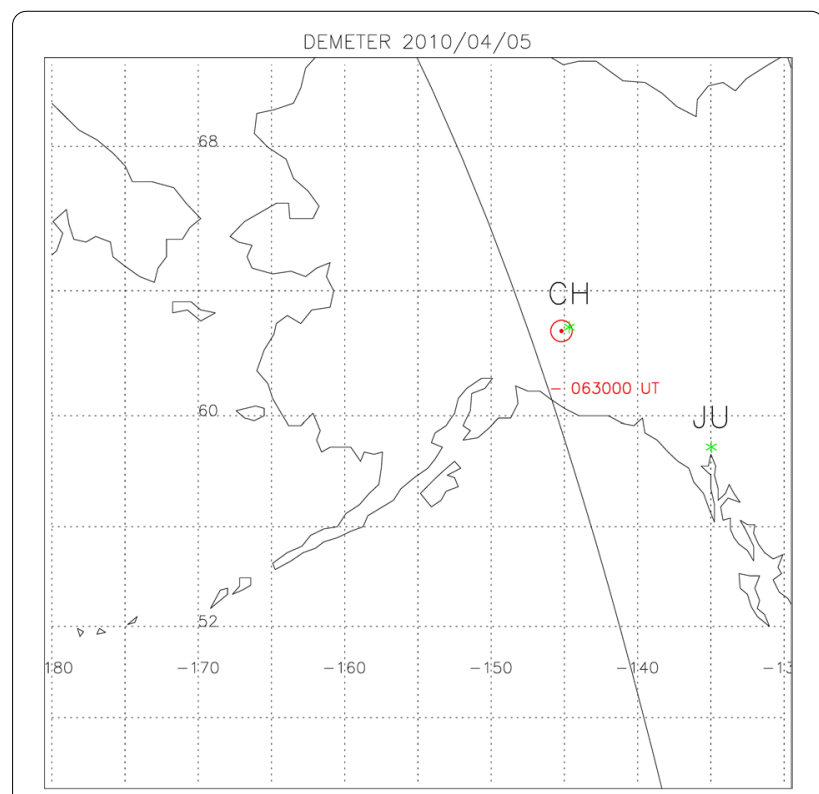

Fig. 27 Map showing the orbit of DEMETER on April 5, 2010 and the HAARP location (red symbol). The positions of Chistochina and Juneau are also indicated right-handed circularly polarized $\left(E_{\mathrm{B}}\right.$ is close to +1$)$. One can see that the $\theta$ values vary as function of time. Outside the trough the propagation is not field-aligned (high $\theta$ values), but inside, the $\theta$ values are much lower.

Concerning the propagation, the analysis indicates in the bottom panel that the pulses are propagating in the opposite direction of the Earth's magnetic field (blue part). As the case 6 takes place in the northern hemisphere, it means that the pulses are propagating upward as expected. The ELF/VLF pulses are generated in the D region of the ionosphere by HAARP, i.e., below the satellite (see for example, Fig. 1 of Piddyachiy et al. 2008).

\section{Discussion}

The main results from the different cases are summarized in Table 1. It is shown that the HAARP pulses are a good substitute for PLHR. In cases 1 and 2, one can see that the emitted pulses can trigger emissions which are very similar to emissions triggered by PLHR (e.g., Figure 5 of Parrot and Němec 2009).

The first example of formation of a set of magnetospheric lines is given in the case 3 where emissions with faller tones are observed in the Southern hemisphere. These emissions return in the Northern hemisphere where they are observed at Juneau. The case 4 is a case where DEMETER is in burst mode in the Northern hemisphere and in the Southern hemisphere close to the conjugate of HAARP. In the two time intervals one can see on the DEMETER spectrograms bursts of rising tones around a couple of pulses with close frequencies. These bursts do not specially follow the time occurrence of the pulses. In the South it leads to the appearance of MLR in the low-resolution spectrogram.

The case 5 is a perfect example of MLR event observed in the Northern hemisphere at Juneau and in both hemispheres by DEMETER. This is a long-duration event lasting more than $43 \mathrm{~min}$ which combines the main features of the previous cases. The detailed spectral analysis of this complex event shows the influence of the HAARP pulses and their propagation to generate MLR which are the result of sidebands, spectral broadening, increase of intensity, and QP emissions. Similar spectral broadening has been observed in the past with pulses emitted by VLF ground-based transmitters (Bell et al. 1983; Inan and Bell 1985, and references therein). Gołkowski et al. (2008) have also observed spectral broadening of the HAARP pulses and shift of their central frequency. It is attributed, together with the increase of intensity, to the equatorial wave-particle interaction. These wave-particle interactions are enhanced when the magnetic activity is sustained in order to have enough particles in the equatorial region. Effectively a study with all MLR events recorded by DEMETER indicates that they statistically occur $17 \mathrm{~h}$ 


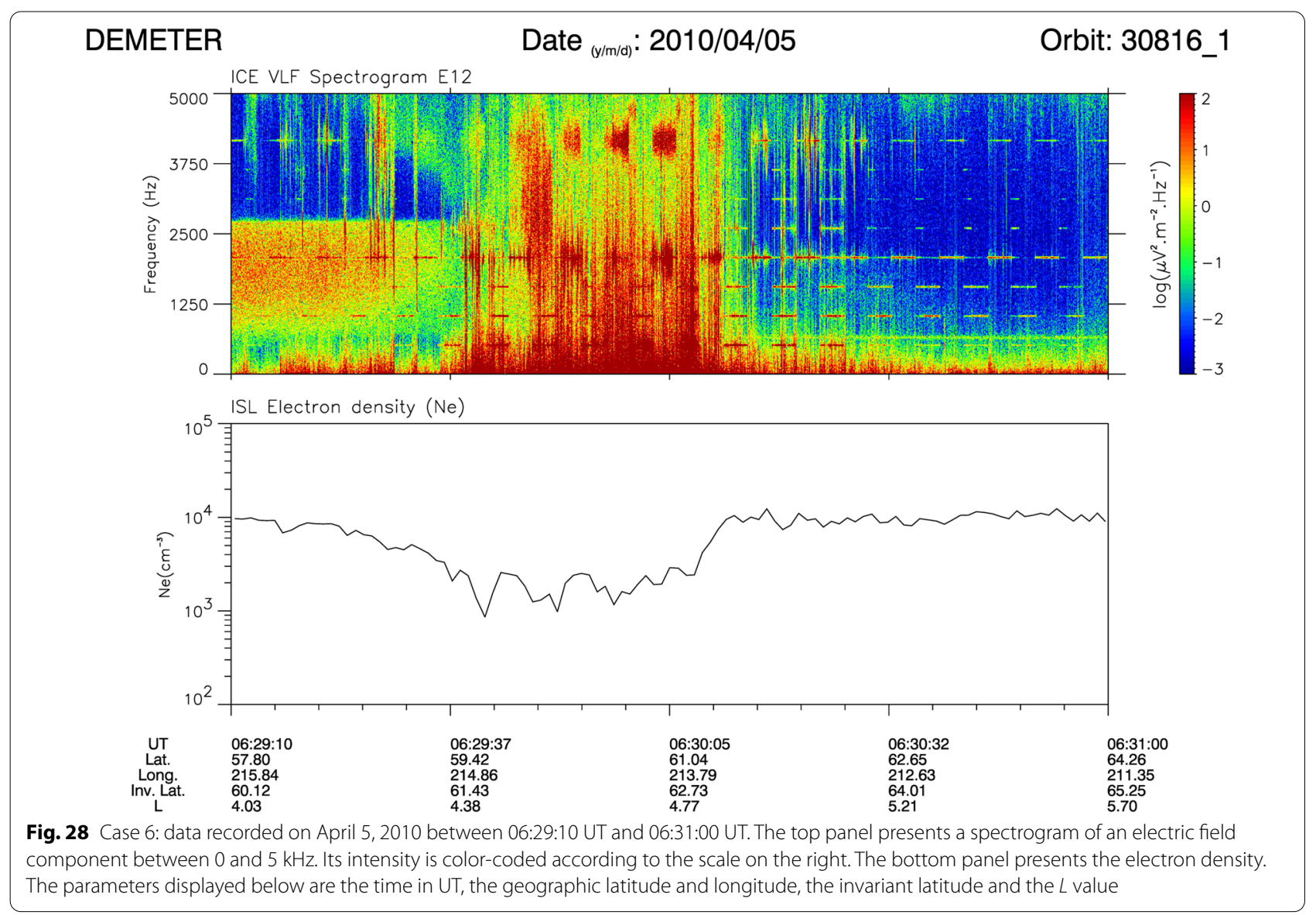

after a decrease of the Dst index, the lowest mean value being equal to $-23.7 \mathrm{nT}$ (Němec et al. 2009a). Our MLR events in case 3, 4, and 5 have been also registered after a weak magnetic activity (for example Dst $=-24 \mathrm{nT}$ on May 5, 2008).

It has been previously shown that sidebands can be triggered by coupling between a VLF transmitter pulse and a natural ELF emission (Bell 1985; Sotnikov et al. 1991, and references therein). Costabile et al. (2017) posit that the sidebands are generated as a result of oscillation of the electron phase-space hole at the trapping frequency, creating a hybrid amplitude/frequency modulation of the injected pulse. Sidebands can also be produced by two beating waves. Several sidebands have been observed by Helliwell et al. (1986) when two monochromatic signals closely spaced in frequency have been emitted from Siple in Antartica and received at Roberval (Quebec) the conjugate station. They even said that the triggering of several frequency emissions with close frequencies will lead to a noise-like spectrum similar to the mid-latitude hiss. In fact it is the effect we can notice at the end of the case 5 in Fig. 24. Rastani et al. (1985) also report observation by a satellite of sidebands around
Siple pulses. It was additionally found by Gołkowski et al. (2019) that sideband amplitude of HAARP pulses may be symmetrical or asymmetrical about the frequency carrier, and in the asymmetrical case it is usually the upper sideband that is stronger.

The 1-hop time duration, which is experimentally determined, is between 3.1 and $4.5 \mathrm{~s}$ because it depends on the conditions of propagation and density along the path. This 1-hop time is similar to previous observations of HAARP echoes (Inan et al. 2004; Gołkowski et al. 2008). The calculation shows that the largest observed value $(\sim 5.5 \mathrm{~s}$ in the case 5 for the snake ramp) can be obtain if, under quiet conditions and parallel propagation at $L=5.1$, we assume an equatorial electron density of $400 \mathrm{~cm}^{-3}$ (inside the plasmapause).

Nunn et al. (1999) said that the strongest power line frequencies are only observed at high harmonics due to the power system used by industrial plants. But pulses emitted by HAARP to simulate PLHR have been also observed at specific frequencies although they have been really emitted in a large frequency range if we consider the harmonics. It means that there is a problem of propagation and/or attenuation for pulses at particular 


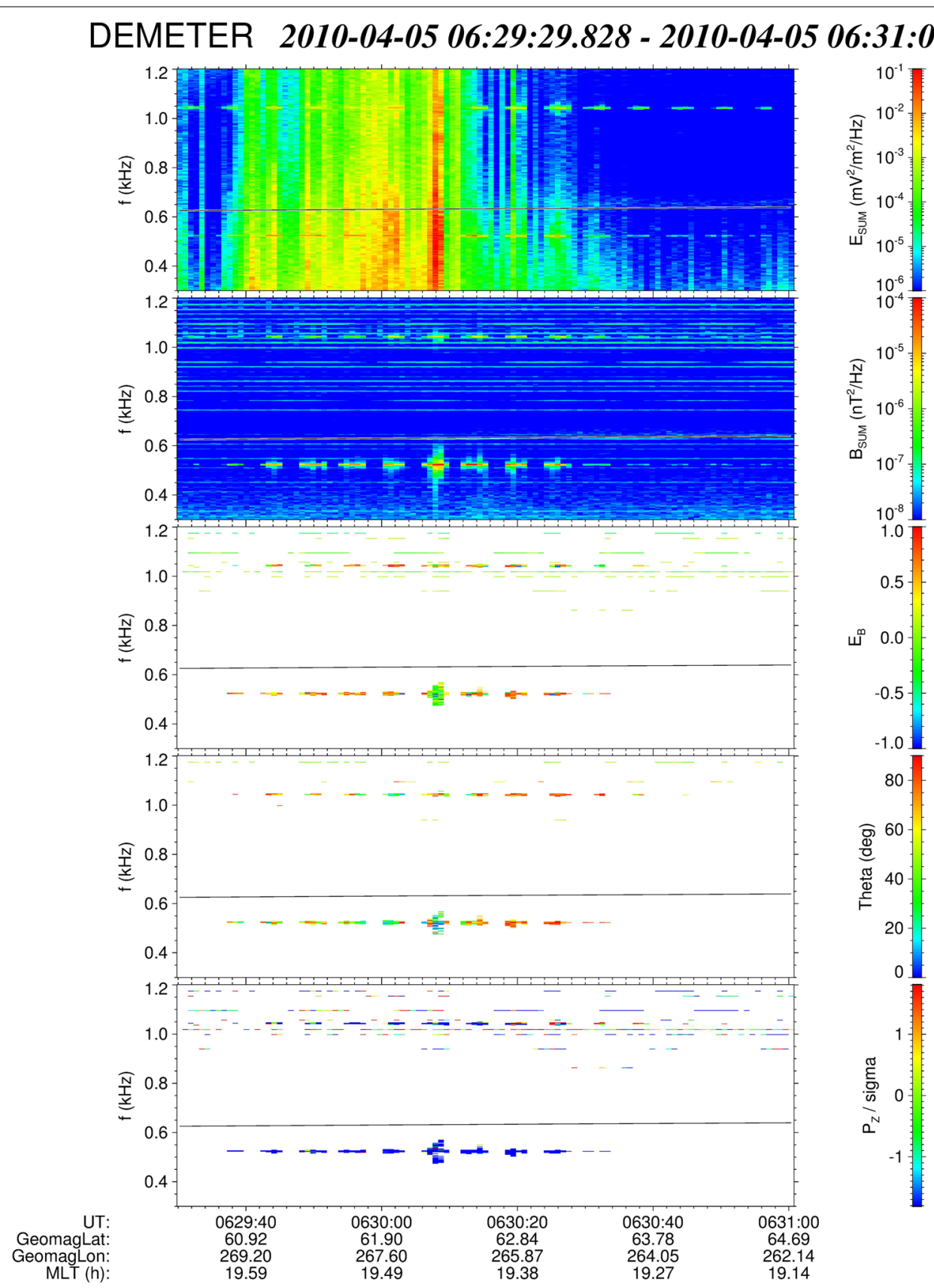

Fig. 29 Wave propagation analysis of the case 6 shown in Fig. 28 between 06:29:30 and 06:31:00 UT. From the top to the bottom: the magnetic field spectrogram, the electric field spectrogram, the ellipticity of magnetic field, the polar angle $\theta$, and the Poynting vector component along the terrestrial magnetic field normalized by the standard deviation (see text for explanation). All parameters are color-coded according to the scales on the right. The frequency range is from $300 \mathrm{~Hz}$ up to $1.2 \mathrm{kHz}$. In each panel the line just above $600 \mathrm{~Hz}$ represents the proton gyrofrequency. The parameters displayed on the abscissa are the time in UT, the geomagnetic latitude and longitude, and the magnetic local time

frequencies. In all cases this is shown (see Table 1). It seems that there are a lower and an upper frequency cutoff depending on the plasma parameters, and that the parent pulses or the echoes can be only observed in a frequency window. For example, DEMETER in the North can observe 2-hop echoes but not Chistochina in the cases 2, 4 (North) and 5, although in the case 4 (South) the 2-hop echoes can reach the ground. The cases, where 2-hop echoes are observed on board DEMETER but not at the ground stations below, also show the observation 
Table 1 Summary of the observations for the different cases defined by the DEMETER half-orbit number and the date

\begin{tabular}{|c|c|c|c|c|c|c|}
\hline Case & Orbit/date & HAARP & DEMETER & Chistochina & Juneau & 1-hop time \\
\hline \multirow[t]{4}{*}{1} & 16781.0 & $571 \mathrm{~Hz}$ & South 1-hop & No data & 2-Hop & \\
\hline & Day & $1973 \mathrm{~Hz}$ & $2 \mathrm{kHz}+\mathrm{TR}$ & & $2 \mathrm{kHz}+\mathrm{TR}$ & $4.0 \mathrm{~s}$ \\
\hline & $2007 / 08 / 23$ & $2011 \mathrm{~Hz}$ & & & & \\
\hline & & $\mathrm{R}: 0-2 \mathrm{kHz}$ & & & & \\
\hline \multirow[t]{8}{*}{2} & 16883.0 & $571 \mathrm{~Hz}$ & North 2-hop & Pulses at $2 \mathrm{kHz}+$ harmonics of $571 \mathrm{~Hz}$ & No data & \\
\hline & Day & $1973 \mathrm{~Hz}$ & $2 \mathrm{kHz}+\mathrm{TR}$ & & & $4.5 \mathrm{~s}$ \\
\hline & 2007/08/30 & $2011 \mathrm{~Hz}$ & & & & \\
\hline & & $\mathrm{R}: 0-2 \mathrm{kHz}$ & & & & \\
\hline & & $1710 \mathrm{~Hz}$ & South 1-hop & Pulses at all freq. + harmonics & No data & \\
\hline & & $1890 \mathrm{~Hz}$ & $1710 \mathrm{~Hz}+\mathrm{TR}$ & & & \\
\hline & & $2370 \mathrm{~Hz}$ & $1890 \mathrm{~Hz}+\mathrm{TR}$ & & & \\
\hline & & R: $0.5-3.5 \mathrm{kHz}$ & & & & \\
\hline \multirow[t]{4}{*}{3} & 20534.1 & $571 \mathrm{~Hz}$ & South 1-hop & Pulses at $1713 \mathrm{~Hz}+2 \mathrm{kHz}$ & 2-hop & \\
\hline & Night & $1973 \mathrm{~Hz}$ & $1713 \mathrm{~Hz}+\mathrm{QP}$ & & $1713 \mathrm{~Hz}+\mathrm{QP}$ & $3 s$ \\
\hline & $2008 / 05 / 05$ & $2011 \mathrm{~Hz}$ & & & & \\
\hline & & $\mathrm{R}: 0-2 \mathrm{kHz}$ & & & & \\
\hline \multirow[t]{8}{*}{4} & 20585.0 & $500 \mathrm{~Hz}$ & North 2-hop & Pulses at all freq. + harmonics & No data & \\
\hline & Day & $2575 \mathrm{~Hz}$ & $2.5-2.7 \mathrm{kHz}+\mathrm{TR}$ & & & $4 s$ \\
\hline & $2008 / 05 / 08$ & $2755 \mathrm{~Hz}$ & & & & \\
\hline & & $3235 \mathrm{~Hz}$ & & & & \\
\hline & & $2375 \mathrm{~Hz}$ & South 1-hop & 2-hop & No data & \\
\hline & & $2555 \mathrm{~Hz}$ & $2.3-2.6 \mathrm{kHz}+\mathrm{TR}$ & All freq. $+2375 \mathrm{~Hz}+\mathrm{TR}$ & & \\
\hline & & $3035 \mathrm{~Hz}$ & & & & \\
\hline & & $\mathrm{R}: 0.5-3.5 \mathrm{kHz}$ & & & & \\
\hline \multirow[t]{6}{*}{5} & 20614.0 & $1110 \mathrm{~Hz}$ & North 2-hop & & 2-hop & $3.15 \mathrm{~s}$ \\
\hline & Day & $1525 \mathrm{~Hz}$ & $2125 \mathrm{~Hz}+\mathrm{TR} / \mathrm{QP}$ & & $2125 \mathrm{~Hz}+\mathrm{TR} / \mathrm{QP}$ & \\
\hline & $2008 / 05 / 10$ & $2125 \mathrm{~Hz}$ & & Pulses & & \\
\hline & & $\mathrm{R}: 1.3-2.3 \mathrm{kHz}$ & $2220 \mathrm{~Hz}+\mathrm{SR}$ & $1525 \mathrm{~Hz}$ & & \\
\hline & & $\mathrm{R}: 0.8-2.8 \mathrm{kHz}$ & South 1-hop & $2125 \mathrm{~Hz}$ & 2-hop & $3.1 \mathrm{~s}$ \\
\hline & & SR: $0.8-2.8 \mathrm{kHz}$ & $\sim 2 \mathrm{kHz}+\mathrm{TR} / \mathrm{QP}$ & $2220 \mathrm{~Hz}+\mathrm{R}+\mathrm{SR}$ & $\sim 2 \mathrm{kHz}+\mathrm{TR} / \mathrm{QP}$ & \\
\hline \multirow[t]{3}{*}{6} & 30816.1 & $520.8 \mathrm{~Hz}$ & North pulses & No data & No data & \\
\hline & Night & $2083 \mathrm{~Hz}$ & $520.8 \mathrm{~Hz}$ & & & \\
\hline & $2010 / 04 / 05$ & & $2083 \mathrm{~Hz}+$ harmonics & & & \\
\hline
\end{tabular}

The frequencies of the pulses and the ramps ( $S R$ is for snake ramp) emitted by HAARP are indicated together with the frequencies of the pulses observed by DEMETER in the northern or in the southern hemisphere, and by the ground stations Chistochina and Juneau. TR is for triggered emissions and QP for quasi-periodic emissions

of 2-hop echoes at geomagnetic footprints hundreds of km away from HAARP. For a 2-hop echo to return to the northern hemisphere, the path must be ducted or plasmapause guided in the equatorial region since unguided whistler mode waves in a smooth plasmasphere quickly propagate across L-shells. The waves thus observed must exit their ducted paths above the DEMETER spacecraft. A diversity of guiding structures and irregularities can thus be concluded. Sometimes ducts extend well into the ionosphere $(100 \mathrm{~km})$ allowing 2-hop echoes to be observed on the ground, other times the ducts likely terminate at $1000 \mathrm{~km}$ altitude.
The wave propagation analysis of the pulses in the case 6 indicates that they propagate in the whistler mode. Then propagation of HAARP pulses must suffer the same constraints as the propagation of usual whistlers. This whistler propagation has been already widely discussed in the past. The ionospheric and magnetospheric propagation of whistlers is mainly controlled by the lower hybrid resonance (LHR) frequency, the equatorial electron gyrofrequency, and the presence of high-or low-density ducts (see for example Bošková et al. 1988; Streltsov et al. 2006; Gołkowski et al. 2019; Xu et al. 2020). Normally whistlers emitted in a hemisphere cannot reach the ground 
in the opposite hemisphere but the ground-based receivers show that it does. Whistlers at any frequency can be guided by low-density ducts, whereas whistlers in highdensity ducts can only propagate for frequencies below half the equatorial gyrofrequency $(\sim 3.7 \mathrm{kHz}$ for $L=4.9)$. Then in some events, $3.7 \mathrm{kHz}$ must be an upper cutoff frequency of the HAARP pulses. It is all the more true since it has been reported that artificial ducts of density enhancement can be created under certain conditions by the high-power HF radio waves emitted by the Sura facility (Frolov et al. 2008) or HAARP (Milikh et al. 2008; Vartanyan et al. 2012).

Concerning the LHR frequency, when the whistlers are going to higher latitudes unguided waves that propagate at oblique wave-normal angles suffer an LHR reflection at low altitudes. The reflection occurs when the frequency of the whistlers approaches the local LHR frequency. The lowest frequency of the spectra represents the highest LHR frequency along the propagation path. In order to have an evaluation of the LHR frequency $f_{\mathrm{LHR}}$ above HAARP, we use the classic expression:

$$
f_{\mathrm{LHR}}^{2}=\frac{1}{M_{\mathrm{eff}}} \frac{f_{\mathrm{c}}^{2} f_{\mathrm{p}}^{2}}{f_{\mathrm{c}}^{2}+f_{\mathrm{p}}^{2}},
$$

where $f_{\mathrm{c}}$ is the electron gyrofrequency $\left(f_{\mathrm{c}}\right.$ in $\mathrm{Hz}=28 * B$, where $B$ is in $\mathrm{nT}), f_{\mathrm{p}}$ is the plasma frequency $\left(f_{\mathrm{p}}\right.$ in $\mathrm{Hz}=9 * n_{\mathrm{e}}^{1 / 2}$, where $n_{\mathrm{e}}$ is in $\mathrm{m}^{-3}$ ), and $M_{\text {eff }}$ is the dimensionless effective ion mass determined by the relation

$$
\frac{1}{M_{\mathrm{eff}}}=\frac{m_{\mathrm{e}}}{n_{\mathrm{e}}} \sum_{\text {ions }} \frac{n_{\alpha}}{m_{\alpha}}
$$

Here $n_{e}, m_{e}$ are the electron density and mass, respectively, $n_{\alpha}, m_{\alpha}$ are the same for ions of species $\alpha$, and summation is assumed over all ion species. The altitude profile of the Earth's magnetic field $B$ is given by the IGRF model (Thébault et al. 2015), whereas the altitude profiles of electron and ion densities are given by the IRI2016 model (Bilitza et al. 2017). Note that, for simplicity, the $f_{\text {LHR }}$ profiles are calculated right above HAARP and its magnetically conjugate point and not along the expected propagation path of the pulses but this will not invalidate the following explanations.

The LHR frequency profiles shown in Fig. 30 have been evaluated for the two local times of DEMETER (10.5 and 22.5). It can be seen that there is a slight dissymmetry between the two conjugate points because the $B$ profiles and the densities profiles are not identical. First, if we consider the normal $f_{\text {LHR }}$ profiles in the Northern hemisphere (black lines), the important fact is that, whether in day or in nighttime, it is impossible for a whistler emitted in the Northern hemisphere at a frequency less than $\sim 8 \mathrm{kHz}$ to normally propagate in the South and
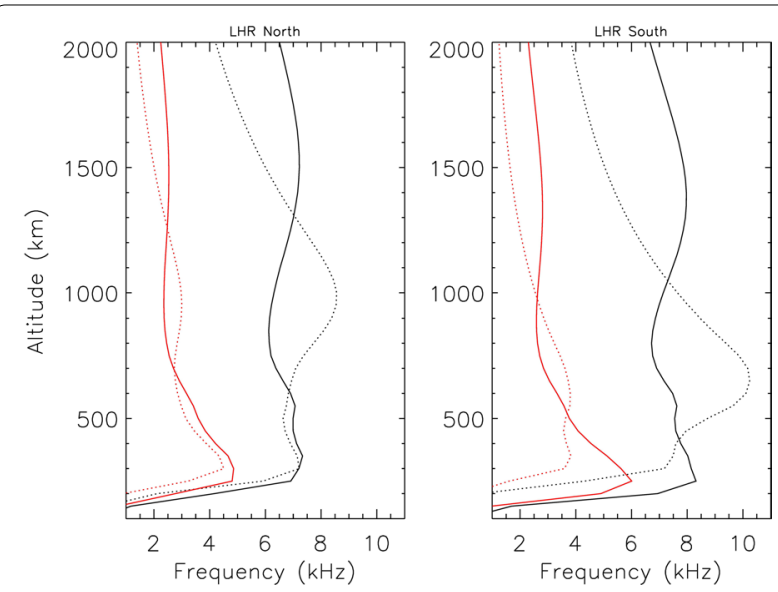

Fig. 30 LHR frequency profiles above HAARP (left panel) and its magnetically conjugate point (right panel) during day time (full lines) and nighttime (dotted lines). The red lines represent the LHR frequency profiles when the electron density given by the IRI2016 model is divided by 10 (see text)

to reach the satellite which is at $660-\mathrm{km}$ altitude above HAARP. Whistlers will be detected only by a satellite moving above the upper maximum of the $f_{\text {LHR }}$ altitude profile. Second, we consider the density profiles in disturbed conditions (red curves) in Fig. 30 which have been obtained with a normal electron density divided by 10 in order to take into account density decrease in depletion ducts as it is for the trough of case 6 (see the bottom panel of Fig. 28). One can see that we have now a rough estimate of the frequencies we can observe on DEMETER, i.e., a whistler with frequencies larger than $\sim 2 \mathrm{kHz}$ coming from the South is able to reach the satellite in the North and oppositely. Normally this whistler cannot reach the ground without attenuation. This problem was theoretically analyzed by Bespalov et al. (2018). It is generally admitted that the whistlers coming from the opposite hemisphere can only reach the ground if the waves propagate in a duct. But recently, Shklyar and Prokhorenko (2020) using numerical simulations have shown that attenuated waves can be observed in any cases. To resume, whistler waves at frequencies higher than about $2 \mathrm{kHz}$ are less attenuated by the propagation. This is well confirmed by Nermec et al. (2009a) who have shown with a statistical analysis of about 650 MLR events recorded by DEMETER that they have a peak of occurrence at a frequency equal to $3 \mathrm{kHz}$ (see their Fig. 10).

\section{Conclusions}

ELF waves emitted by HAARP in the lower ionosphere have been used to replicate the PLHR and to study its effects. Pulses of different lengths and different frequencies have been triggered in order to investigate their 
propagation. Data were simultaneously recorded by two ground-based experiments located in Alaska close to HAARP (Chistochina and Juneau), and by the low-altitude satellite DEMETER when it was above HAARP or its magnetically conjugate point. Six cases have been analyzed which reveal the following points:

- Pulses triggered by HAARP are appropriate to simulate PLHR. They propagate in the whistler mode.

- 2-hop echoes are often observed.

- The propagation of pulses around $2 \mathrm{kHz}$ is less attenuated and this is partially attributed to the LHR frequency and the equatorial electron gyrofrequency.

- We often observe a periodicity of the triggered or QP emissions at times different that the periodicity of the pulses seen on the ground. It means that the pulses are important for the initial generation of the emissions, but once the emissions are generated, the periodicity might be (at least partly) determined by the bounce period rather than solely by the radiated pattern.

- Looking to the end of the case 5 in Fig. 20, one can see that the MLR tends to disappear and to be more like a diffuse noise similar to hiss. Then this kind of event can be considered as one of the hiss generation mechanisms which is under debate since a long time (see Thorne et al. 1979, and more recently Tsurutani et al. 2018, 2019, and references therein).

In conclusion, it is shown that any monochromatic waves emitted at a frequency around $2 \mathrm{kHz}(1.5-2.5 \mathrm{kHz})$ even during a rather short time can lead to the formation of MLR because during their propagation back and forth in the magnetosphere, they are submitted to the physical processes described above (sidebands, spectral broadening, equatorial increase of the intensity, triggered emissions, frequency dispersion). Are there such natural monochromatic waves in the ionosphere? In the past, two kinds of electromagnetic emissions with frequency line structures have been observed by DEMETER, but it was during very high magnetic activity and at lower frequencies because they were related to ion gyrofrequencies. The first were located in the trough (Parrot et al. 2006), and the second were located in the equatorial region (Němec et al. 2016; Parrot et al. 2016). Since all DEMETER MLR events (including cases 3,4 , and 5) were recorded after a weak magnetic activity at high latitudes and at higher frequencies, we can conclude that only man-made waves emitted by power lines can be the cause of MLR.

\section{Abbreviations}

PLHR: Power Line Harmonic Radiation; MLR: Magnetospheric Line Radiation; HAARP: High-frequency Active Auroral Research Program; DEMETER:
Detection of Electro-Magnetic Emissions Transmitted from Earthquake Regions;; FFT: Fast Fourier transform; TEM: Transverse electro-magnetic; MLT: Magnetic local time; UT: Universal time; LT: Local time; QP: Quasi-periodic; HF: High frequency; ELF: Extremely high frequency; VLF: Very low frequency; wrt: With regard to; IGRF: International Geomagnetic Reference Field; DMT: DEMETER; SVD: Singular value decomposition; LHR: Lower hybrid resonance; CNES: Centre National d'Etudes Spatiales; ICE: Instrument Champ Electrique; ISL: Instrument Sonde de Langmuir; PI: Principal investigator; GACR: Grantová Agentura České Republiky; CDPP: Centre des Données de la Physique des Plasmas; WALDO: Worldwide Archive of Low-frequency Data and Observations; LPC2E: Laboratoire de Physique et Chimie de I'Environnement et de l'Espace; CNRS: Centre National de la Recherche Scientifique.

\section{Acknowledgements}

The satellite DEMETER was operated by the French Centre National d'Etudes Spatiales (CNES). A part of this work is based on observations with the electric field experiment ICE and the Langmuir probe experiment ISL embarked on DEMETER. The authors thank J.J. Berthelier and J.P. Lebreton the PIs of these experiments for the use of the data. M. Gołkowski was supported by NASA Grant 80NSSC19K0264. F. Němec would like to acknowledge the support of GACR Grant 21-01813S.

\section{Authors' contributions}

MP, FN, MC and MG designed this study. FN and MP took care of the DEMETER data, whereas MC and MG provided their HAARP expertise. FN and MP prepared the figures. MP prepared the draft. FN, MC and MG revised the draft. All authors discussed the results. All authors read and approved the final manuscript.

\section{Funding}

Not applicable.

\section{Availability of data and materials}

The DEMETER data shown in this paper can be obtained at https://cdpp-archi ve.cnes.fr/. The Alaska ground-based data can be downloaded from https:// waldo.world/. The values of the Earth's magnetic field and the electron and ion density altitude profiles have been extracted on line from https://ccmc. gsfc.nasa.gov/modelweb/models/igrf_vitmo.php and https://ccmc.gsfc.nasa. gov/modelweb/models/iri2016_vitmo.php, respectively. The magnetic activity has been checked with the Dst index using http://wdc.kugi.kyoto-u.ac.jp/dst_ final/index.html.

\section{Declarations}

\section{Competing interests}

The authors declare that they have no competing interests regarding the publication of this paper.

\section{Author details}

${ }^{1}$ LPC2E/CNRS, Orléans, France. ${ }^{2}$ Université d'Orléans, Orléans, France. ${ }^{3}$ Faculty of Mathematics and Physics, Charles University, Prague, Czech Republic.

${ }^{4}$ School of Electrical and Computer Engineering, Georgia Institute of Technology, Atlanta, GA, USA. ${ }^{5}$ Department of Electrical Engineering, University of Colorado Denver, Denver, CO, USA.

Received: 15 September 2021 Accepted: 25 November 2021

Published online: 04 January 2022

\section{References}

Bell TF (1985) High amplitude VLF transmitter signals and associated sidebands observed near the magnetic equatorial plane on the ISEE 1 satellite. J Geophys Res 90:2792-2806

Bell TF, Luette JP, Inan US (1982) ISEE 1 observations of VLF line radiation in the Earth's magnetosphere. J Geophys Res 87(A5):3530-3536

Bell TF, James HG, Inan US, Katsufrakis JP (1983) The apparent spectral broadening of VLF transmitter signals during transionospheric propagation. J Geophys Res 88:4813-4840 
Bespalov PA, Mizonova VG, Savina ON (2018) Reflection from and transmission through the ionosphere of VLF electromagnetic waves incident from the mid-latitude magnetosphere. J Atmos Sol Terr Phys 175:40-48

Bezděková B, Němec F, Parrot M, Santolík O, Kruparova O (2015) Magnetospheric line radiation: 6.5 years of observations by the DEMETER spacecraft. J Geophys Res Space Phys 120(11):9442-9456

Bezděková B, Němec F, Parrot M, Hajoš M, Záhlava J, Santolík O (2019) Dependence of properties of magnetospheric line radiation and quasiperiodic emissions on solar wind parameters and geomagnetic activity. J Geophys Res Space Phys 124(4):2552-2568

Bilitza D, Altadill D, Truhlik V, Shubin V, Galkin I, Reinisch B, Huang X (2017) International reference ionosphere 2016: from ionospheric climate to real-time weather predictions. Space Weather 15:418-429

Bošková J, Jiř́ček F, Shklyar DR, Titova EE, Tríska P (1988) LHR whistlers in the outer ionosphere as observed on satellites. Adv Space Res 8(8):133-136

Cohen MB (2009) ELF/NLF phased array generation via frequency matched steering of a continuous HF ionospheric heating beam. Ph.D. Thesis, Stanford University

Cohen M (2020) Returning lightning data to the cloud. Eos. 101

Cohen MB, Gołkowski M (2013) 100 days of ELF/NLF generation via HF heating with HAARP. J Geophys Res Space Phys 118:6597-6607

Cohen MB, Gołkowski M, Inan US (2008) Orientation of the HAARP ELF ionospheric dipole and the auroral electrojet. Geophys Res Lett 35:L02806. https://doi.org/10.1029/2007GL032424

Cohen MB, Inan US, Paschal EW (2010a) Sensitive broadband ELFNLF radio reception with the AWESOME instrument. IEEE Trans Geosci Remote Sens 48(1):3-16. https://doi.org/10.1109/TGRS.2009.2028331

Cohen MB, Said RK, Inan US (2010b) Mitigation of 50/60 Hz power-line interference in geophysical data. Radio Sci 45(6):1-12. https://doi.org/10.1029/ 2010 RS004420

Cohen MB, Inan US, Piddyachiy D, Lehtinen NG, Gołkowski M (2011) Magnetospheric injection of ELFNLF waves with steerable HF heating of the lower ionosphere. J Geophys Res 116:A06308. https://doi.org/10.1029/2010J A016194

Cohen MB, Golkowski M, Lehtinen NG, Inan US, McCarrick MJ (2012) HF beam parameters in ELFNLF wave generation via modulated heating of the ionosphere. J Geophys Res 117:A05327. https://doi.org/10.1029/2012JA017585

Costabile JD, Gołkowski M, Wall RE (2017) Modulation analysis of whistler mode sidebands in VLF-triggered emissions and implications for conditions of nonlinear growth. J Geophys Res Space Phys 122:12505-12516. https://doi.org/10.1002/2017JA024501

Dudkin F, Korepanov V, Dudkin D, Pilipenko V, Pronenko V, Klimov S (2015) Electric field of the power terrestrial sources observed by microsatellite Chibis-M in the Earth's ionosphere in frequency range $1-60 \mathrm{~Hz}$. Geophys Res Lett 42(14):5686-5693

Frolov VL, Rapoport VO, Komrakov GP, Belov AS, Markov GA, Parrot M, Rauch JL, Mishin EV (2008) Density ducts formed by heating the Earth's ionosphere with high-power HF radio waves. JETP Lett 88(12):790-794

Gołkowski M (2009) Magnetospheric wave injection by modulated HF heating of the auroral electrojet. Ph.D. Thesis, Stanford University

Gołkowski M, Inan US, Gibby AR, Cohen MB (2008) Magnetospheric amplification and emission triggering by ELFNLF waves injected by the $3.6 \mathrm{MW}$ HAARP ionospheric heater. J Geophys Res 113:A10201. https://doi.org/10. 1029/2008JA013157

Gołkowski M, Inan US, Cohen MB, Gibby AR (2010) Amplitude and phase of nonlinear magnetospheric wave growth excited by the HAARP HF heater. J Geophys Res 115:A00F04. https://doi.org/10.1029/2009JA014610

Gołkowski M, Cohen MB, Carpenter DL, Inan US (2011) On the occurrence of ground observations of ELFNLF magnetospheric amplification induced by the HAARP facility. J Geophys Res 116:A04208. https://doi.org/10. 1029/2010JA016261

Gołkowski M, Harid V, Hosseini P (2019) Review of controlled excitation of non-linear wave-particle interactions in the magnetosphere. Front Astron Space Sci 6:2

Guo Z, Fang H, Honary F (2021) The generation of ULF/ELF/NLF waves in the ionosphere by modulated heating. Universe 7:29. https://doi.org/10. 3390/universe7020029

Helliwell RA, Katsufrakis JP, Bell TF, Raghuram R (1975) VLF line radiation in the Earth's magnetosphere and its association with power system radiation. J Geophys Res 80(31):4249-4258
Helliwell RA, Inan US, Katsufrakis JP, Carpenter DL (1986) Beat excitation of whistler mode sidebands using the Siple VLF transmitter. J Geophys Res Space Phys 91(A1):143-153

Hosseini P, Gołkowski M, Turner DL (2017) Unique concurrent observations of whistler mode hiss, chorus, and triggered emissions. J Geophys Res Space Phys 122:6271-6282

Inan US, Bell TF (1985) Spectral broadening of VLF transmitter signals observed on DE 1: a quasi-electrostatic phenomenon? J Geophys Res Space Phys 90(A2):1771-1775

Inan US, Gołkowski M, Carpenter DL, Reddell N, Moore RC, Bell TF, Paschal E, Kossey P, Kennedy E, Meth SZ (2004) Multi-hop whistler-mode ELFNLF signals and triggered emissions excited by the HAARP HF heater. Geophys Res Lett 31:L24805. https://doi.org/10.1029/2004GL021647

Koons HC, Dazey MH, Edgar BC (1978) Satellite observation of discrete VLF line radiation within transmitter-induced amplification bands. J Geophys Res 83(A8):3887-3889

Kostrov AV, Gushchin ME, Strikovskii AV (2017) Generation and radiation of high power line harmonics. Geomagn Aeron 57(4):482-490

Manninen J (2005) Power line harmonic radiation, magnetospheric line radiation. Some aspects of ELF-VLF emissions in geophysical research, vol 98. Oulu University Press, Oulu

Matthews JP, Yearby K (1978) Magnetospheric VLF line radiation observed at Halley, Antarctica. Planet Space Sci 29:97-106

Milikh G, Papadopoulos K, Shroff H, Chang C, Wallace T, Mishin E, Parrot M, Berthelier J-J (2008) Formation of artificial ionospheric ducts. Geophys Res Lett 35:L17104. https://doi.org/10.1029/2008GL034630

Němec F, Santolík O, Parrot M, Berthelier J-J (2006) Power line harmonic radiation (PLHR) observed by the DEMETER spacecraft. J Geophys Res 111:A04308. https://doi.org/10.1029/2005JA011480

Němec F, Santolík O, Parrot M, Berthelier J-J (2007) Comparison of magnetospheric line radiation and power line harmonic radiation: a systematic survey using the DEMETER spacecraft. J Geophys Res 112:A04301. https:// doi.org/10.1029/2006JA012134

Němec F, Santolík O, Parrot M, Bortnik J (2008) Power line harmonic radiation observed by satellite: properties and propagation through the ionosphere. J Geophys Res 113:A08317. https://doi.org/10.1029/2008J A013184

Němec F, Parrot M, Santolík O, Rodger CJ, Rycroft MJ, Hayosh M, Shklyar D, Demekhov A (2009a) Survey of magnetospheric line radiation events observed by the DEMETER spacecraft. J Geophys Res 114:A05203. https:// doi.org/10.1029/2008JA014016

Němec F, Raita T, Parrot M, Santolík O, Turunen T (2009b) Conjugate observations on board a satellite and on the ground of a remarkable MLR-like event. Geophys Res Lett 36:L22103. https://doi.org/10.1029/2009GL040974

Němec F, Parrot M, Santolík O (2010) Influence of power line harmonic radiation on the VLF wave activity in the upper ionosphere: is it capable to trigger new emissions? J Geophys Res 115:A11301. https://doi.org/10. 1029/2010JA015718

Němec F, Parrot M, Santolík O (2012a) Detailed properties of magnetospheric line radiation events observed by the DEMETER spacecraft. J Geophys Res 117:A05210. https://doi.org/10.1029/2012JA017517

Němec F, Santolík O, Parrot M, Pickett JS (2012b) Magnetospheric line radiation event observed simultaneously on board Cluster 1, Cluster 2 and DEMETER spacecraft. Geophys Res Lett 39:L18103. https://doi.org/10. 1029/2012GL053132

Němec F, Parrot M, Santolík O (2015) Power line harmonic radiation observed by the DEMETER spacecraft at $50 / 60 \mathrm{~Hz}$ and low harmonics. J Geophys Res Space Phys 120(10):8954-8967

Nĕmec F, Parrot M, Santolík O (2016) Equatorial noise emissions observed by the DEMETER spacecraft during geomagnetic storms. J Geophys Res Space Phys 121:9744-9757. https://doi.org/10.1002/2016JA023145

Nunn D, Manninen J, Turunen T, Trakhtengerts V, Erokhin N (1999) On the nonlinear triggering of VLF emissions by power line harmonic radiation. Ann Geophys 17(1):79-94

Park CG, Helliwell RA (1978) Magnetospheric effects of power line radiation. Science 200:727-730

Park CG, Helliwell RA (1981) Power line radiation in the magnetosphere. Adv Space Res 1:423-437

Park CG, Helliwell RA (1983) Ground observations of power line radiation coupled to the ionosphere and magnetosphere. Space Sci Rev 35:131-137 
Park CG, Miller TR (1979) Sunday decreases in magnetospheric VLF wave activity. J Geophys Res Space Phys 84(A3):943-950

Parrot M (2006) First results of the DEMETER micro-satellite. Planet Space Sci $54(5)$

Parrot M, Němec F (2009) MLR events and associated triggered emissions observed by DEMETER. Adv Space Res 44:979-986

Parrot M, Buzzi A, Santolík O, Berthelier J-J, Sauvaud J-A, Lebreton JP (2006) New observations of electromagnetic harmonic ELF emissions in the ionosphere by the DEMETER satellite during large magnetic storms. J Geophys Res 111:A08301. https://doi.org/10.1029/2005JA011583

Parrot M, Manninen J, Santolík O, Němec F, Turunen T, Raita T, Macúšová E (2007) Simultaneous observation on board a satellite and on the ground of large-scale magnetospheric line radiation. Geophys Res Lett 34:L19102. https://doi.org/10.1029/2007GL030630

Parrot M, Nĕmec F, Santolík O (2014) Statistical analysis of VLF radio emissions triggered by power line harmonic radiation and observed by the lowaltitude satellite DEMETER. J Geophys Res Space Phys 119(7):5744-5754

Parrot M, Nĕmec F, Santolík O, Cornilleau-Wehrlin N (2016) Equatorial noise emissions with a quasiperiodic modulation observed by DEMETER at harmonics of the O+ ion gyrofrequency. J Geophys Res Space Phys 121:10289-10302. https://doi.org/10.1002/2016JA022989

Piddyachiy D (2012) Propagation of ELF waves generated by an HF ionospheric heater in the Earth's plasma environment. Ph.D. thesis, Stanford University, California, USA

Piddyachiy D, Inan US, Bell TF, Lehtinen NG, Parrot M (2008) DEMETER observations of an intense upgoing column of ELFNLF radiation excited by the HAARP HF heater. J Geophys Res 113:A10308. https://doi.org/10.1029/ 2008JA013208

Piddyachiy D, Bell TF, Berthelier J-J, Inan US, Parrot M (2011) DEMETER observations of the ionospheric trough over HAARP in relation to HF heating experiments. J Geophys Res Space Phys. https://doi.org/10.1029/2010」 A016128

Platino M, Inan US, Bell TF, Parrot M, Kennedy EJ (2006) DEMETER observations of ELF waves injected with the HAARP HF transmitter. Geophys Res Lett 33:L16101. https://doi.org/10.1029/2006GL026462

Rastani K, Inan US, Helliwell RA (1985) DE-1 observations of Siple transmitter signals and associated sidebands. J Geophys Res 90(A5):4128-4140

Rodger CJ, Thomson NR, Dowden RL (1995) VLF line radiation observed by satellite. J Geophys Res 100(A4):5681-5689

Rodger CJ, Clilverd MA, Yearby KH, Smith AJ (1999) Magnetospheric line radiation observations at Halley, Antarctica. J Geophys Res 104(A8):17441-17447

Rodger CJ, Clilverd MA, Yearby KH, Smith AJ (2000a) Is magnetospheric line radiation man-made? J Geophys Res 105:15981-15990

Rodger CJ, Clilverd MA, Yearby KH, Smith AJ (2000b) Temporal properties of magnetospheric line radiation. J Geophys Res 105(A1):329-336

Santolík O, Lefeuvre F, Parrot M, Rauch JL (2001) Complete wave-vector directions of electromagnetic emissions: application to INTERBALL-2 measurements in the nightside auroral zone. J Geophys Res 106:13191-13201

Santolík O, Parrot M, Lefeuvre F (2003) Singular value decomposition methods for wave propagation analysis. Radio Sci 38(1):1010. https://doi.org/10. 1029/2000RS002523

Sheerin JP, Cohen MB (2015) Nonlinear plasma experiments in geospace with gigawatts of RF power at HAARP. AIP Conf Proc 1689:020003. https://doi. org/10.1063/1.4936465

Shklyar DR, Prokhorenko SA (2020) Reflection from the ionosphere and exit to the ground of whistler wave packets: a dynamical model. J Atmos Sol Terr Phys 201:105222

Sotnikov VI, Fiala V, Lefeuvre F, Lagoutte D, Mogilevsky M (1991) Excitation of sidebands due to nonlinear coupling between a VLF transmitter signal and a natural ELF emission. J Geophys Res Space Phys 96(A7):11363-11369

Streltsov AV, Lampe M, Manheimer W, Ganguli G, Joyce G (2006) Whistler propagation in inhomogeneous plasma. J Geophys Res 111:A03216. https://doi.org/10.1029/2005JA011357

Thébault E, Finlay CC, Beggan CD, Alken P, Aubert J, Barrois O et al (2015) International geomagnetic reference field: the 12th generation. Earth Planets Space 67(1):1-19. https://doi.org/10.1186/s40623-015-0228-9

Thorne RM, Church SR, Gorney DJ (1979) On the origin of plasmaspheric hiss: the importance of wave propagation and the plasmapause. J Geophys Res 84:5241-5247. https://doi.org/10.1029/JA084iA09p05241
Tomizawa I, Yoshino T (1985) Power line radiation observed by the satellite. J Geomagn Geoelectr 37:309-327

Tsurutani BT, Park SA, Falkowski BJ, Lakhina GS, Pickett JS, Bortnik J et al (2018) Plasmaspheric hiss: coherent and intense. J Geophys Res Space Phys 123:10009-10029. https://doi.org/10.1029/2018JA025975

Tsurutani BT, Park SA, Falkowski BJ, Bortnik J, Lakhina GS, Sen A et al (2019) Low frequency $(f<200 \mathrm{~Hz})$ polar plasmaspheric hiss: coherent and intense. J Geophys Res Space Phys 124(12):10063-10084

Vartanyan A, Milikh GM, Mishin E, Parrot M, Galkin I, Reinisch B, Huba J, Joyce G, Papadopoulos K (2012) Artificial ducts caused by HF heating of the ionosphere by HAARP. J Geophys Res 117:A10307. https://doi.org/10. 1029/2012JA017563

Xu X, Chen L, Zhou C, Liu X, Xia Z, Simpson JJ, Zhang Y (2020) Two-dimensional full-wave simulation of whistler mode wave propagation near the local lower hybrid resonance frequency in a dipole field. J Geophys Res Space Phys 125(4):e2019JA027750

Yearby KH (1982) Magnetospheric VLF line radiation, Ph.D. Thesis, University of Sheffield, UK. http://etheses.whiterose.ac.uk/21743/1/256707.pdf

Yearby KH, Smith AJ, Bullough K (1983) Power line harmonic radiation in Newfoundland. J Atmos Terr Phys 45:409-419

\section{Publisher's Note}

Springer Nature remains neutral with regard to jurisdictional claims in published maps and institutional affiliations.

\section{Submit your manuscript to a SpringerOpen ${ }^{\circ}$ journal and benefit from:}

- Convenient online submission

- Rigorous peer review

- Open access: articles freely available online

- High visibility within the field

- Retaining the copyright to your article

Submit your next manuscript at $\boldsymbol{\nabla}$ springeropen.com 